\title{
Building Girls' Protective Assets: A Collection of Tools for Program Design
}

Population Council

Follow this and additional works at: https://knowledgecommons.popcouncil.org/departments_sbsr-pgy

Part of the Demography, Population, and Ecology Commons, Family, Life Course, and Society Commons, Gender and Sexuality Commons, International Public Health Commons, and the Women's Health Commons How does access to this work benefit you? Let us know!

\section{Recommended Citation}

Population Council. 2016. "Building Girls' Protective Assets: A Collection of Tools for Program Design." New York: Population Council. 


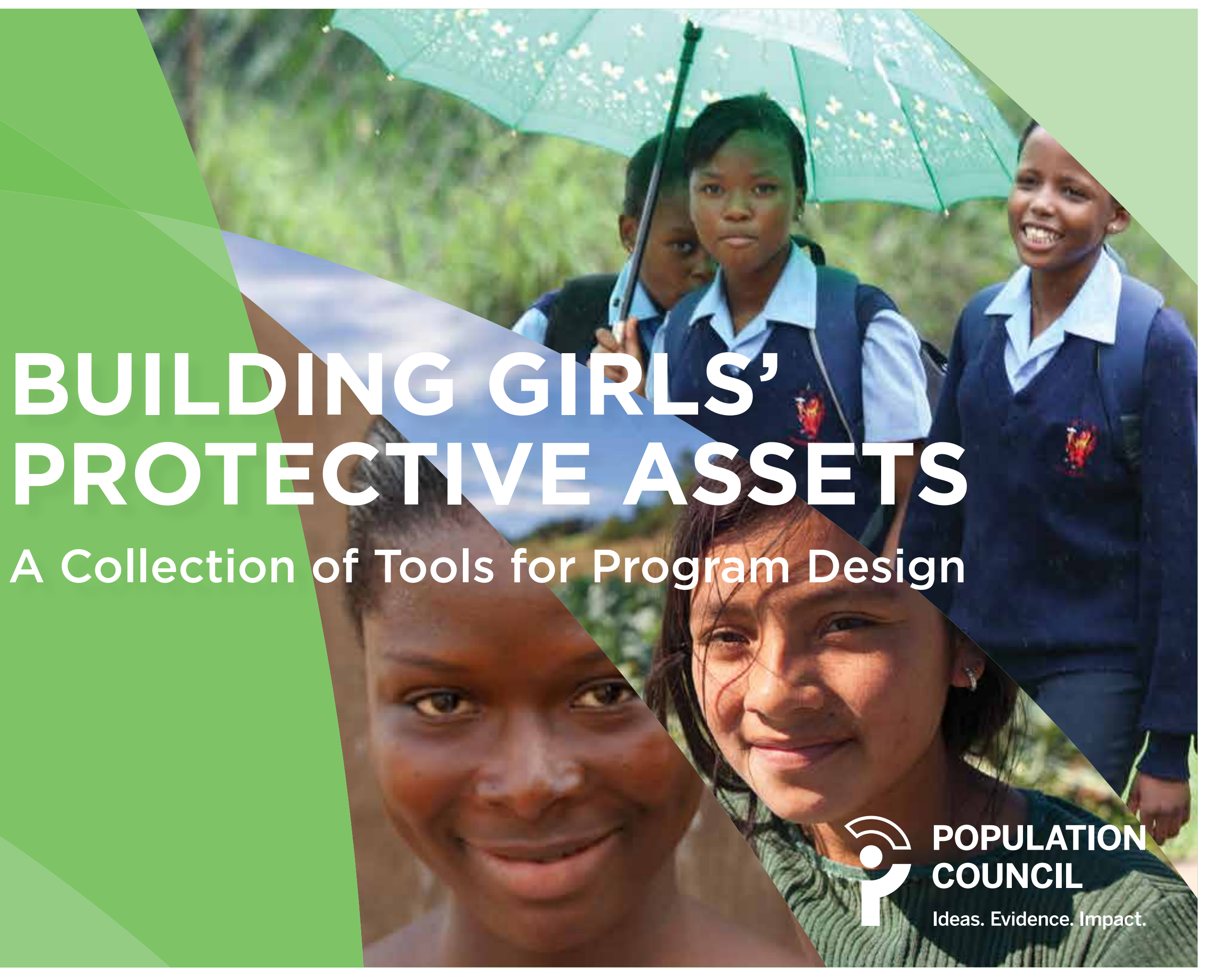


The Population Council confronts critical health and

development issues-from stopping the spread of HIV to

improving reproductive health and ensuring that young people

lead full and productive lives. Through biomedical, social

science, and public health research in 50 countries, we work

with our partners to deliver solutions that lead to more effective policies, programs, and technologies that improve lives around

the world. Established in 1952 and headquartered in New York,

the Council is a nongovernmental, nonprofit organization

governed by an international board of trustees.

\section{Population Council}

One Dag Hammarskjold Plaza

New York, NY 10017 USA

popcouncil.org

email: publications@popcouncil.org

ISBN: 978-0-87834-137-4

C) 2016 The Population Council, Inc.

Updated December 2016

Suggested citation: Population Council. 2016. Building Girls Protective Assets: A Collection of Tools for Program Design.

New York: Population Council. 


\section{BUILDING GIRLS' PROTECTIVE ASSETS}

A Collection of Tools for Program Design 


\section{ACKNOWLEDGMENTS}

This collection, based on the experiences of dozens of programs that work with adolescent girls, would not have been possible without the willingness of many people to share their successes, stumbling blocks, and expertise. Many of the tools in the collection first appeared in other toolkits. Foremost among the collection's sources are the Population Council's Girl-Centered Program Design: A Toolkit to Develop, Strengthen \& Expand Adolescent Girls Programs, which follows the full program planning cycle, and the forthcoming Girls' Participatory Action Quantified Tools (G-PAQT) Kit. We recognize the invaluable contributions of the researchers who developed, tested, and authored these and other toolkits so that programmers could benefit from their research findings. Among our Council colleagues, we would like to give our thanks to Karen Austrian, Chernor Bah, Martha Brady, Judith Bruce, Alejandra Colom, Angel del Valle, Sarah Engebretsen, Annabel Erulkar, Dennitah Ghati, Kelly Hallman, Eunice Muthengi, Craig Savel, and Dana Smiles for generously sharing their expertise and resources.

Thank you to the Women's Refugee Commission - Omar J. Robles and Dale Buscher in particular - for its partnership on the development and field-testing of the Girl Roster and on the programmatic implications of its results in humanitarian context. As a critical thought partner, the Women's Refugee Commission continues to support the Girl Roster's evolution and foster its ever-growing use as part of the I'm Here approach. The Population Council also acknowledges its partners in the Girls in Emergencies Collaborative who have applied resources and concepts outlined in this publication.

Thank you to Eva Roca and Kristen Woolf for their creativity and knowledge on several graphics and worksheets. Many thanks to Andrew Karlyn, Vira David, Sarah Blake, and Audrey Anderson for being key thought partners in the Girl Roster's development and to Veronica Torres and Adam Weiner for their contribution to worksheets and exercises found within this publication. Thank you to Amy Babchek, Ann Blanc, Sophie Soares, and Miriam Temin for their careful review, edit, and input on the layout and contents. Thanks also to the Population Council's Office of Publishing and Creative Services for editing and design. Finally, our most important thanks is to those who inspired this collection: the adolescent girls who bring the purpose of these tools to life and give meaning to the work we all do.

Our hope is that the tools in this collection will help ensure that no one misses out on the rising tide of action to help the hundreds of millions of adolescent girls and young women in low- and middle-income countries make a safe transition to adulthood, fulfill their potential, and live lives free from HIV, violence, and other threats to their well-being. 
Adolescent girls have become a key target population for empowerment, health, and development initiatives in low- and middle-income countries. Building Girls' Protective Assets: A Collection of Tools for Program Design is intended for organizations that are committed to extending their programs to reach excluded subpopulations of girls and young women-whether they are the poorest girls in the poorest communities, the 10-14-year-old girls who are out of school and not living with either parent, or another subpopulation of young girls that is likely to miss out.

The collection contains tools and exercises to help programmers translate evidence on "what works" into girl-centered programming. The resources in this collection focus on programs that have been effective-through empowerment and the building of protective assets-in reducing girls' risks and broadening their opportunities.

The tools and exercises in this collection will help program staff:

- assess and adjust current target groups and establish new target groups to ensure they are reaching those most in need of protective assets;

- adapt program materials to respond to the reality of girls' lives; and

- monitor and evaluate to measure effects and adjust activities to increase impact. 


\section{The Protective Asset-Building Approach}

The tools and exercises in this collection enable those who are designing and implementing girl-centered programs to integrate the Population Council's "Protective AssetBuilding Approach". Using this approach, program staff can improve their activities' coverage, that is not only how

many of the most in-need girls they reach but also that they reach enough of them to make a difference, ultimately enhancing the program's impact. Assets are defined as the store of human stock that helps girls safely navigate a variety of risks as they age.

The fundamental concepts of protective asset-building are explained in the Protective Asset Building Strategy House. These fundamental concepts provide the organizing structure for this collection.

Each tool and exercise is color-coded to align with the fundamental concept on which it is based.

\section{Our vision:}

Adolescent girls transition safely to adulthood
Start with the girls to see the girls.

Girls are a key target population for many health initiatives, but without intentional recruitment efforts those most in need are overlooked. Some elite," where those who are better off benefit from the program. Program designs that are based on information about the full universe of girls and young women in an area are more likely to reach those who are socially excluded than programs that rely on demand-led recruitment. empowerment and programs "capture the
Segment to find the right girls.

To achieve a sustainable impact, it is vital for girl-centered programs to reach the right girls and young women. and young women.
Rather than treating Rather than treating
girls and young women girls and young wo
as a homogenous group, it is important to understand the unique risks and opportunities facing different subpopulations or segments and to tailor accordingly. By reaching the right girls and young women within their segments, it is possible to reach enough of them-a sustainable difference. program materials is possible to reach critical mass-to make a
Concentrate on the "walkable community."

To understand girls' and young women's circumstances, program staff need to focus on the access they have to resources within their walkable communitythe resources and structures they can structures they can reach that provide personal safety and allow them to take action. Their "community" should be defined not only by their physical boundaries, but also the people and resources that define their social space.
Establish community-based platforms.

All girls and young women-especially those who are socially isolated-need places where they can meet regularly with peers and mentors. When these places are accessible, private, and safe, they serve as community-based platforms for delivering a range of interventions to segments of girls and young women who gather within them. These platforms can
become a place where excluded girls and

young women gain voice and agency. young women who
Build social and other protective assets.

An asset is a store of value-which can

be tangible or

intangible-that

programs build to

empower girls and

young women and

enable them to reduce

their risks and expand

their opportunities. For

example, programs can

help provide and

strengthen protective

assets such as identity

cards, self-efficacy

about condom use,

numeracy, or social

support that girls can

use to negotiate daily

risks or to protect their

savings. Protective

assets can be

categorized as human,

social, economic,

and cognitive.

\section{Overcome exclusion}

Protective Asset-Building Strategy House 


\section{Stepwise Design Process for an Asset-Building Program}

Basing program decisions about design, implementation, and monitoring on local information is fundamental to the protective asset-building approach. The Council's experience confirms that girl-centered programs that are based on reliable, contextspecific information-rather than on a pre-existing program design or untested assumptions-are better able to reach their intended beneficiaries and achieve their objectives.

A number of helpful steps can support learning along the course of planning, implementing, and monitoring an evidence-based program. These steps are summarized in the Stepwise Design Process for an Asset-Building Program. This design process can help integrate the concepts of the "Protective Asset-Building Approach" into your girl-centered program. No matter where you are along the stepwise design process, it is possible to go back and refine previous steps taken or use what was gained from one step to inform others.

\section{Establish metrics}

\section{Define content}

Gather information

Recruit mentors

Recruit girls

Identify locations and times

Gain community buy-in

Assess risk per segment

Enumerate girl universe
Stepwise Design Process for an Asset-Building Program

Define boundaries and map 


\section{What's in the collection?}

The collection includes tools and exercises that have been designed-and in most cases tested-by the Population Council. The Council and partners have developed these practical resources based on many years of rigorous research on the best ways to reach girls and young women, reduce their risk of negative outcomes, and help them chart a safe transition to adulthood. The expansion of HIV-prevention programming for adolescent girls and young women in 10 high-burden countries under the DREAMS Partnership ${ }^{1}$ was the original impetus for this collection of tools and exercises. Beyond DREAMS, this collection is useful for all who are designing and implementing programs for girls.

The tools can be used to answer one or more of the following:

- Which girls live in your program community?

- How do you engage the right girls?

-Who is your program reaching?

- What physical and social resources as well as hazards are based in your community?

- How do girls judge their safety and access to resources in the community?

-What are the girls' perceptions of organizations in their community?

-What time of day should program activities take place?

-What do girls need by certain ages in order to thrive?
- What assets can you build?

- How do you measure success?

-Who are the important people in girls' lives?

-Who do girls have sex with in your program community?

- What should mentors do?

-What materials do you need to build assets?

-What are the key design elements of your program?

- How do you know if your program is working?

- How do you measure success?

Most of the tools are included in their entirety in the collection along with an explanation, instructions, and tips on where to find more information. For a few of the tools, the additional step of accessing the tool itself is required-particularly the Girl Roster ${ }^{\mathrm{TM}}$ and the Community Resource Scan, which use mobile phone applications. In the case of the Girl Roster ${ }^{\mathrm{TM}}$, the Population Council provides technical assistance.

\section{How to use the collection}

The primary goals of the resources contained in this collection are to improve the reach and enhance the impact of communitybased programs for excluded adolescent girls and young women. The resources can be used by people who are working with girls in a targeted way for the first time, or those who already have a girls' program and want to strengthen or expand it.

The tools can be used on their own or in combination. For some tools-such as those that use community mapping, a widely used participatory program activity (Corbett et al. 2006) - options for using lower technology (pen and paper) and higher technology (an Android phone and a phone application) are available. Worksheets can be photocopied, enlarged, or recreated as needed.

For each tool, the main intended user group is specified-from girls and young women to parents, program staff, and key stakeholders-but this recommendation is not intended to be restrictive. Each resource can be used by several different groups. 


\section{Who can use this collection?}

The collection is designed primarily for program staff who are responsible for the delivery of girl-centered programming.

A second audience for the collection is facilitators. By this we mean program or nonprogram staff from the area where the program is being implemented (such as girl mentors, peer educators) who can be trained to use these tools within their community.

Finally, and most importantly, the collection contains resources that can be used by girls and young women who are in the segments your program is targeting. By engaging girls' active participation with the tools, facilitators and program managers can gain firsthand experiences and insights into girls' lives.

Some users of this collection will be familiar with the "Protective Asset-Building Approach" and its tools following their participation in a training or other event. The Population Council is available to provide further technical assistance to help users get the most out of the collection's resources, learn from experience in other settings, and gain practical tips for implementation.

More tools and expanded descriptions are available at: http://www.popcouncil.org/girl-centered-program-resources.

\section{Tips for Working Directly with Girls}

Programs designed specifically for adolescent girls are more likely to reach them than generalized programming for youth, orphans, and vulnerable children or other broad population groups. Program staff who use this collection to inform their new work or to update their existing work with adolescent girls should consider the following when using the tools with girls themselves:

- It is best to work with pre-existing groups of girls who trust each other and feel comfortable expressing their ideas to one another and with a facilitator they know and trust.

- Do not rush. Include sessions to demonstrate a tool's use and allow for feedback (approximately three hours total). Provide food and beverages between sessions when multiple tools are used together.

- Confidentiality of responses and safety of participants are important. Identify health and psychosocial services before the exercise, in case a girl reports having experienced violence or abuse.

The tools that are part of the Girls' Participatory Action Quantified Tools (G-PAQT) Kit warrant a special mention. These tools are intended to be used as a set with established groups of girls. The four tools are sequenced to start from the broad to the more personal and intimate levels of information. Thus, when working directly with girls, we recommend using the tools: (1) in the order in which they appear in the collection (Community Mapping Exercise, Venn Diagrams of Institutional Access, Social Capital Game, and Ascertaining Sexual Relationship Types (ASERT) Tool TM), and (2) with the same group of girls, so trust is built along the way. 


\section{TABLE OF CONTENTS}

START WITH THE GIRLS TO SEE THE GIRLS

TOOL

The Girl Rosterim

Which girls live in your program community?

\section{SEGMENT TO FIND THE RIGHT GIRLS}

\section{WORKSHEET}

Recruitment Strategy

How do you engage the right girls?

TOOL

Coverage Exercise

Who is your program reaching?

\section{CONCENTRATE ON THE WALKABLE COMMUNITY...15}

TOOL

Community Resource Scan.

What resources and hazards exist in the community?

TOOL

Community Mapping Exercise.

How do girls judge their safety and access to resources in the community?

TOOL

Venn Diagrams of Institutional Access

What are girls' perceptions of the organizations or groups in their community?

\section{ESTABLISH COMMUNITY-BASED PLATFORMS}

TOOL

Safety Scan

What physical and social resources are based in your community?

WORKSHEET

Timing, Frequency, and Duration of Meetings.

What time of day should your program activities take place?

WORKSHEET

Appropriate Venues

Where should your program be based? doolkit.

What do girls need by certain ages in order to thrive?

WORKSHEET

Defining Achievable Asset Benchmarks .....

What assets can you build by segment by the end of the program?

TOOL

Social Capital Game.

Who are the important people in girls' lives?

TOOL

Ascertaining Sexual Relationship Types (ASERT) ${ }^{\mathrm{TM}}$

Who do girls have sex with in their community?

WORKSHEET

Mentors' Role.

What should mentors do?

WORKSHEET

Turning Protective Assets into Program Content

What materials do you need to build assets?

Program Planning Summary....

What are the key design elements of your program?

\section{MONITOR AND EVALUATE}

WORKSHEET

Sample Intake Register.

Who is participating in your program?

\section{Monitoring and Evaluation......}

What should be measured to assess your program's progress and success?

Protective Asset Outcome Indicators

How do you measure the progress of your asset-building program? 

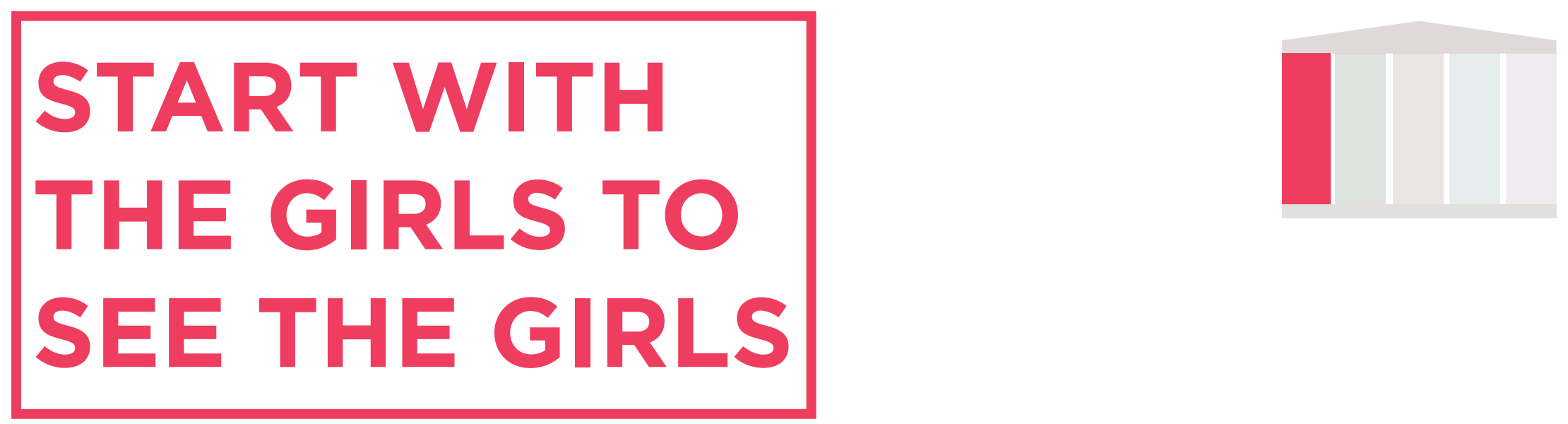

\begin{tabular}{|l|}
\hline ToOL \\
The Girl Roster ${ }^{\text {TM }}$ \\
Which girls live \\
in your program \\
community? \\
pg. 4 \\
\hline
\end{tabular}

Program design choices that are anchored in information about the full universe of girls and young women in a community are more likely to reach those who are socially excluded, which drives benefits to those who need the most support. 


\section{The Girl Roster ${ }^{\mathrm{TM}}$}

The Girl Roster ${ }^{\mathrm{T}}$, developed by the Population Council, Women's Refugee Commission, and partners, ${ }^{2}$ is a practical programming tool to help increase girls' access to vital resources, facilities, and services. It consists of two parts:

1. A household questionnaire that provides a snapshot of how many girls are in the catchment area; and

2. A rapid analysis tool that breaks girls into meaningful segments by age, schooling, and marital, childbearing, and living-arrangement status.

The tool is useful for program managers starting work in a new area and for those wanting to assess and improve their current coverage. It assists program managers in: recognizing the full composition (universe) of girls in a program catchment area by segment; and, through appropriate community engagement, increasing girls' access to a fair share of community resources. Note: The Girl Roster is not intended as a research or monitoring and evaluation tool.

The tool can help programs reach those most in need and bring about measurable changes among them, thus increasing program effectiveness. It was developed to reduce exclusion, recognizing that even with the most equitable of intentions some programs for girls do not apply targeted, evidence-based practices to reach girls and therefore engage fewer girls than they could. Experience consistently shows that some programs "capture the elite," ${ }^{\prime \prime}$ where the majority of the benefits go to girls who are relatively "ontrack" to a safe transition to adulthood, and not those most "off-track." 6

The Girl Roster is freely available from the Population Council. After you access the tool, the Population Council or its partners provide assistance to program staff so they can use the Girl Roster-new cadres of staff are not required-using an Android phone (or in some cases, pencil and paper). It is user-friendly, easy to implement, and has already been applied in approximately 20 diverse settings including Benin, Egypt, Ethiopia, Guatemala, Kenya, South Sudan, Tanzania, and Turkey. 


\section{How to Use the Girl Roster}

The Population Council provides the Girl Roster questionnaire and a rapid analysis output template in Excel. The questionnaire is administered via Android phones (4.0 or higher); it takes approximately seven to ten minutes to conduct per household. You will need, in addition to a phone loaded with the application:

- a laptop or desktop computer

-a wireless Internet connection

-a Gmail account.

The Population Council and its partners are also available to provide technical support through the process.

Step 1. In close collaboration with the Council, make minor adjustments to the questionnaire to suit your required language and location. For example, if the question asks about schooling, you can specify the name of the school; if school content is not only academic but religious, the language can be slightly altered to reflect that.

Step 2. Upload the relevant phone applications and questionnaire to an Android phone and create an account on the online platform through which information will be stored and generated using rapid analysis output template.

Step 3. Collect information by going house-to-house in a "walkable" program community or catchment area as either an individual or pair. Each individual who conducts the Roster is called a rosterer.

Step 4. Generate and interpret the actionable information collected through basic output tables stored on an online platform-the Council provides access-that sort girls in your community into relevant segments.
Step 5. Use this actionable information to identify:

Beneficiaries (based on knowing who lives in the program community)

- Define what on-track and off-track means in your setting; determine who is off-track or likely to slip off-track (stressed yet functioning) and thus a priority for programs and services.

- Define your program's target segments based on how many are on- and off-track.

- Set desired coverage level to achieve saturation within the program community.

- Determine segment-specific recruitment strategies for girls and mentors.

\section{Target communities and locations}

- Map to learn where off-track girls cluster and where girls live in relation to community resources.

- Note meaningful differences between program communities in the proportions of on- and off-track girls, access to community resources, etc.

- Identify appropriate communities and venues for groups of girls to meet within their segments.

\section{Appropriate protective assets to build}

- Identify segment-specific content based on the needs of girl segments. (See "Building Assets Toolkit," pg. 34.)

- Plan the metrics, or achievable benchmarks, of "core" and "desirable" assets you will build for each segment. (See "Defining Achievable Asset Benchmarks Worksheet, pg 36.)

- Arrange for mentor recruitment-who they are; roles and responsibilities; level of compensation. (See "Mentors' Role Worksheet," pg. 43.)

- Use assets to define program content. (See "Turning Protective Assets into Program Content Worksheet," pg. 44.) 


\section{The Girl Roster Questionnaire}

The following are the key questions that compose the crux of the Girl Roster questionnaire, conducted on an Android phone. The phone prompts the rosterer to document identifying information before conducting the interviews. This information includes: ID number, name of the village, and number of the household. The phone also directs rosterers to seek out the female head of household or oldest woman rather than a man, if possible, to direct questions. Finally, rosterers obtain the consent of the household member.

1. How many people live in this household most of the time? Don't forget babies, relatives, household help, and visitors.

2. How many boys and young men ages 0-24 live here? Don't forget babies, relatives, household help, and visitors.

3. How many girls and young women ages 0-24 live here? Don't forget babies, relatives, household help, and visitors.

Please tell me about the girls, starting with the oldest.

1. How old is she?

2. Has she ever gone to school?

3. Is she currently attending school?

4. What is the highest level she completed?

5. Does she have any children?

6. How many children?

7. What is her marital status?

8. Does her mother or father live here?

Separately, use the phone application to mark the GPS coordinates, signifying the location of the household. This will help later identify where girls, per segment, generally live in the community.

With practice, the questions more naturally arise in dialogue. Through this style, rosterers can qualify some questions with commentary and create a more open and comfortable conversation

for the interviewee. For example, they can ask about boys-despite not documenting answers-when household members raise concerns that too much emphasis is being placed on girls. 


\section{Girl Roster: What Comes Next}

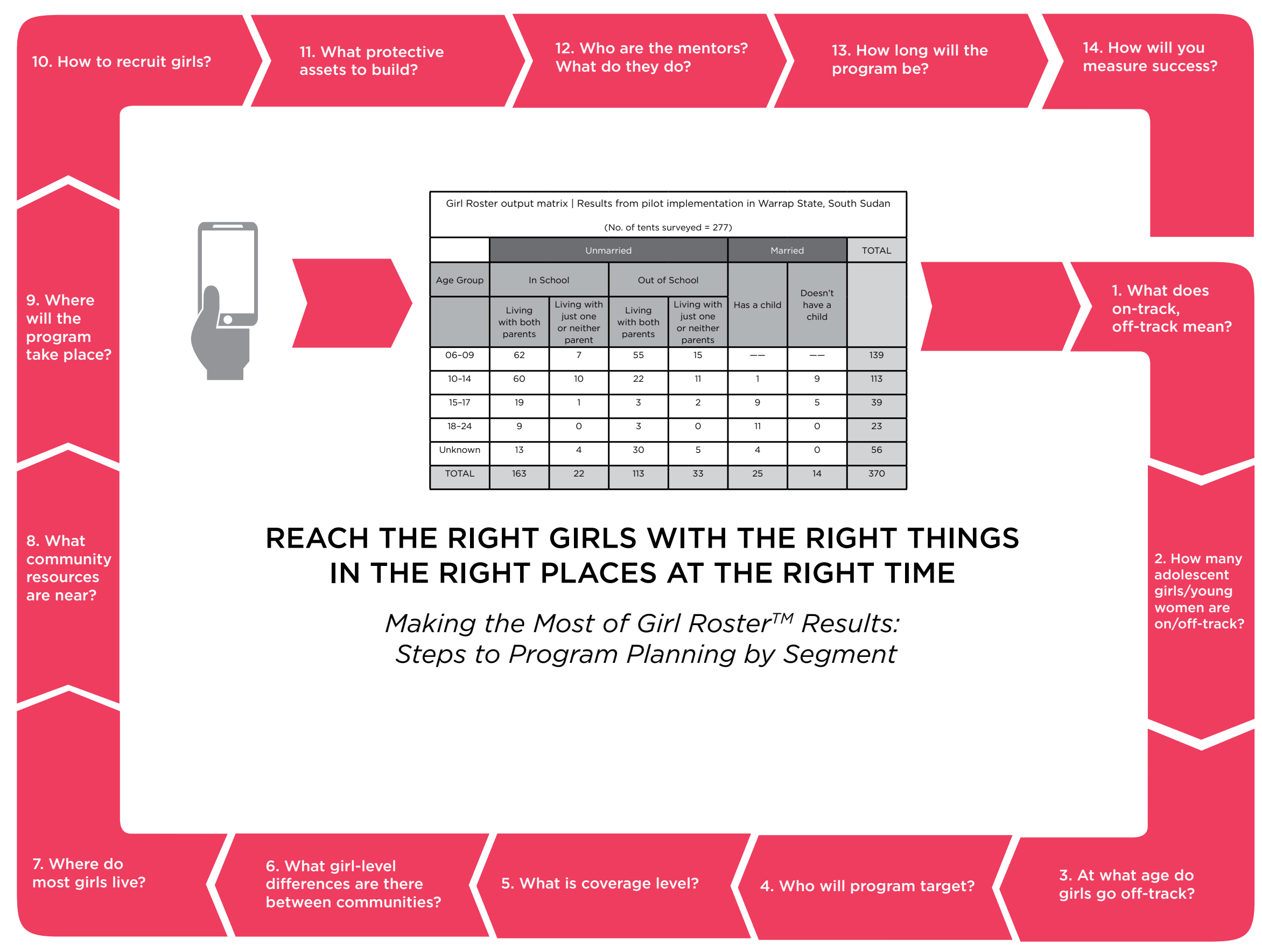




\section{Case Study}

The Girl Roster was implemented in 2014 in a humanitarian camp in South Sudan by the Women's Refugee Commission (Robles 2014). The field team took three days to interview individuals in all tents within the camp-approximately 277 tents/households. With technical assistance from the Council, the team was able to generate an output table (see below), which highlighted inconsistencies between the number of girls rostered and the number of those engaged in the program. The Roster generated many new program considerations; for example, the team identified 39 married adolescent girls and young women, 25 of whom already had at least one child. After interpreting this actionable information from the Roster, coupled with focus groups that highlighted girls' fears concerning accessing health services, one local agency hired a female health worker to provide adolescent-friendly services.

Girl Roster output matrix | Results from pilot implementation in Warrap State, South Sudan

(No. of tents surveyed $=277$ )

\begin{tabular}{|c|c|c|c|c|c|c|c|}
\hline \multirow{3}{*}{ Age Group } & \multicolumn{4}{|c|}{ Unmarried } & \multicolumn{2}{|c|}{ Married } & \multirow[t]{3}{*}{ TOTAL } \\
\hline & \multicolumn{2}{|c|}{ In School } & \multicolumn{2}{|c|}{ Out of School } & \multirow[b]{2}{*}{ Has a child } & \multirow{2}{*}{$\begin{array}{l}\text { Doesn't } \\
\text { have a } \\
\text { child }\end{array}$} & \\
\hline & $\begin{array}{l}\text { Living } \\
\text { with both } \\
\text { parents }\end{array}$ & $\begin{array}{l}\text { Living with } \\
\text { just one } \\
\text { or neither } \\
\text { parent }\end{array}$ & $\begin{array}{l}\text { Living } \\
\text { with both } \\
\text { parents }\end{array}$ & $\begin{array}{l}\text { Living with } \\
\text { just one } \\
\text { or neither } \\
\text { parents }\end{array}$ & & & \\
\hline $06-09$ & 62 & 7 & 55 & 15 & -- & -- & 139 \\
\hline $10-14$ & 60 & 10 & 22 & 11 & 1 & 9 & 113 \\
\hline $15-17$ & 19 & 1 & 3 & 2 & 9 & 5 & 39 \\
\hline $18-24$ & 9 & 0 & 3 & 0 & 11 & 0 & 23 \\
\hline Unknown & 13 & 4 & 30 & 5 & 4 & 0 & 56 \\
\hline TOTAL & 163 & 22 & 113 & 33 & 25 & 14 & 370 \\
\hline
\end{tabular}



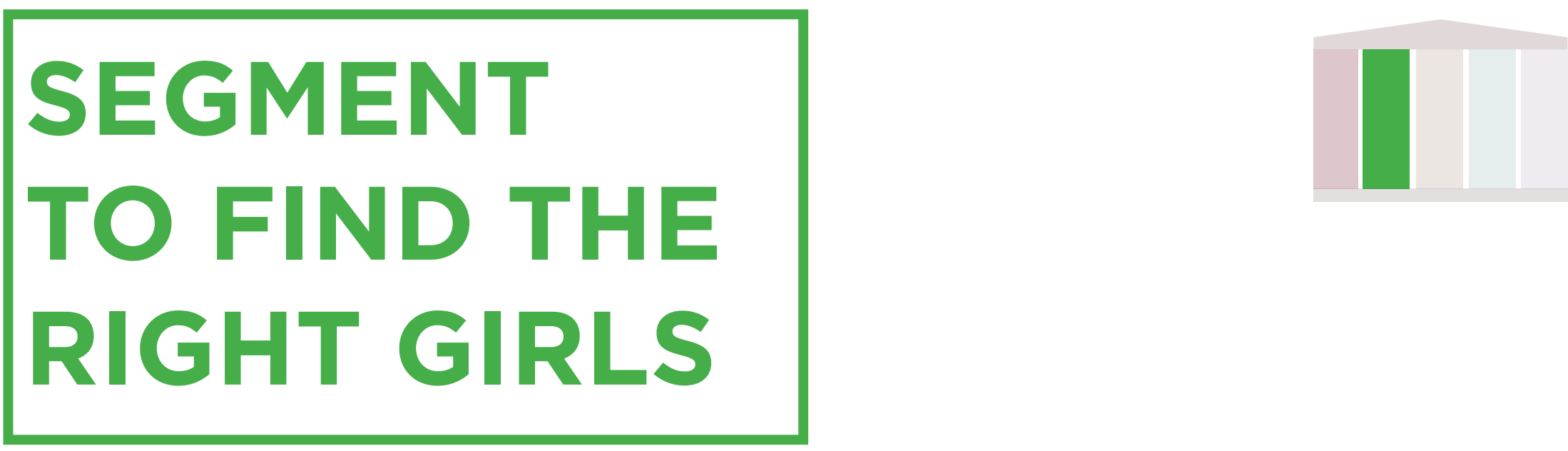

\begin{tabular}{|l|}
\hline WoRKSHEET \\
Recruitment \\
Strategy \\
How do you engage \\
the right girls? \\
$\qquad \mathrm{pg} .10$ \\
\hline
\end{tabular}

\begin{tabular}{|} 
ToOL \\
Coverage Exercise \\
Who is your \\
program reaching? \\
pg. 11
\end{tabular}

By reaching the right girls and young women within their segments, it is possible to reach enough of them-a critical mass-to make a sustainable difference. 


\section{Recruitment Strategy Worksheet}

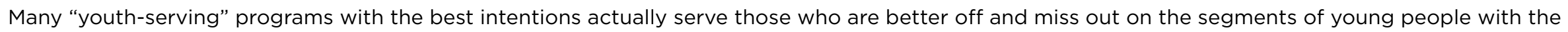

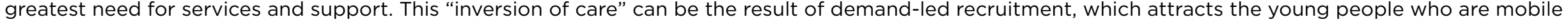

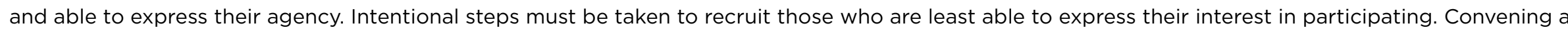

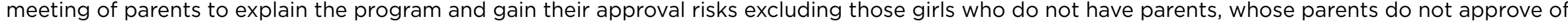

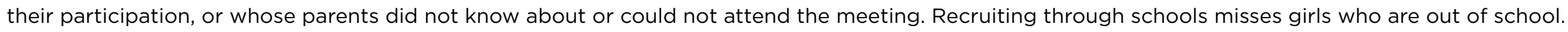
The following worksheet can help you thoroughly assess recruitment options or limitations.

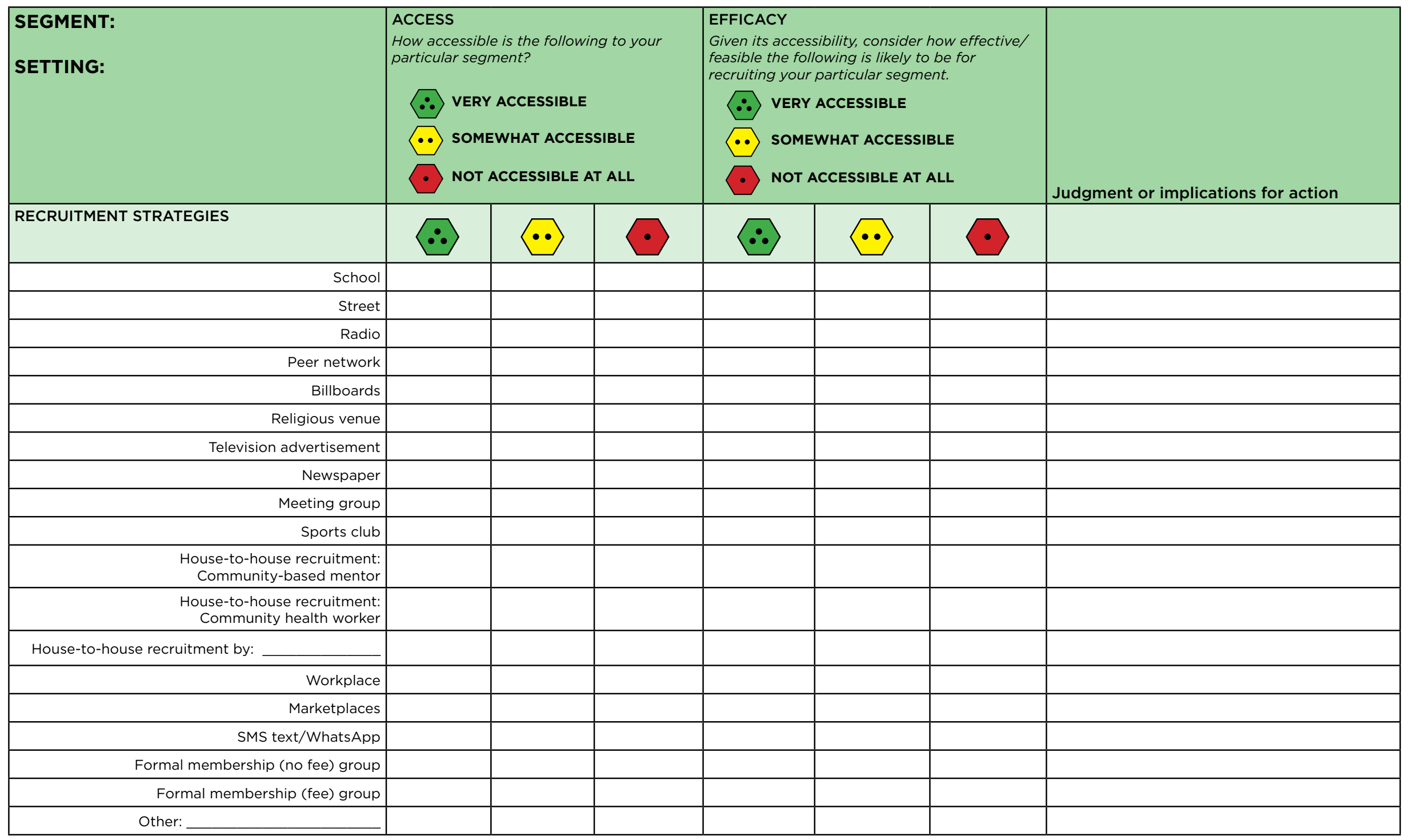




\section{Coverage Exercise}

In girl-centered programs, it is important to understand which segments of girls are not being reached. By understanding reach, program staff can responsibly target groups and make adjustments to programs to reach the intended segment of girls with the appropriate services. The Coverage Exercise (CE) is simple and low cost to implement (Population Council 2006). Understanding whether programs are reaching intended beneficiaries helps implementers and donors focus their activities and funding to reach those most in need or off-track. Results of the CE hold providers accountable and ensure that services and resources intended for girls are actually reaching the segments they planned to reach. This "supply side" analysis tool also helps inform program staff if the types of services or activities are appropriate for the girls receiving them.

A CE describes and counts who is being reached by a service within a particular geographic area and helps determine if a large number of eligible girls or young women have been excluded. The exercise is used to collect information on a variety of characteristics of beneficiaries of a program or service, which enables program staff and managers to look systematically at which services they are providing, to whom and where, and whether program beneficiaries are repeat participants or not. Whereas the Girl Roster (pg. 4) captures the characteristics of girls in a community, the Coverage Exercise tells us the characteristics of the participants-boys and girls-in the program.

Coverage exercises can differ in their depth and detail depending on the goals, for example:

- Providing a snapshot in time of one program: for providers who would like quick results regarding a single program (Austrian and Ghati 2010).

- Monitoring of one program. The CE can be integrated into the ongoing monitoring plan, including repeating CEs at key moments to track if the profile of users has changed in the desired direction (Population Council 2006).

- Providing a snapshot of coverage of multiple programs of one organization. An organization with a number of outlets may want to find out who it is reaching in different locations by collecting data around the same time.
The CE can be used in combination with the Community Resource Scan (pg. 16) and the Venn Diagrams of Institutional Access (pg. 22) to link results on who the programs reach to geographic information on where resources are located and how accessible they are to the girls targeted by the program. After you have identified key resources in the community that you want to build on, you have the option of conducting a CE to profile and quantify who is reached by a given service within a particular geographic area. This tool was developed to assist programs serving youth, but it can be used for a range of services, both those based in a facility and those conducted through outreach. 
How to Use the Tool

Systematically collecting information using a Coverage Exercise can answer questions about your participants, such as:

- how many boys vs. girls

- how many younger vs. older adolescents

- how many are in vs. out of school

- which geographic areas they come from

- which services are more popular among girls vs. boys

This can raise important questions for program staff to answer, such as:

- How can I reach more girls? What changes do I need to make to my program so girls feel safer?

- Do I want to reach more younger girls or boys?

-Why aren't out-of-school girls ages 10-19 coming to my program?

-Why aren't girls from specific areas coming to my program? What can I do to reach out to them?

- What can be done so that we can do a better job of reaching the girls, based on program goals, especially the younger, off-track out-ofschool girls-or do our goals need to be adjusted?

The coverage tool is primarily used to analyze the coverage of an individual program. It can also be used in a whole community with all youth-serving organizations, or in an entire city or even country. The larger analysis of these results would provide an understanding of which young people are reached by "youth-serving organizations"-and who is left out. This can be helpful for planning at all levels from neighborhood to national. The methodology varies depending on your resources and objective.

\section{For More Information}

For more information, read "Assessing equity of access in programs for young people" by Adam Weiner or "Using Data to See and Select the Most Vulnerable Adolescent Girls" by Sarah Engebretsen

http://www.popcouncil.org/uploads/pdfs/TABriefs/28_AssessAccess.pdf http://www.popcouncil.org/uploads/pdfs/2012PGY_GirlsFirst_Data.pdf
Step 1. Pick the critical information that you would like to collect about girls.

For example:

- If you are working with only school-going girls, you want to ask, "What grade are you in?" However, if you are working with a mix of in-school and out-of-school girls, it might be better to ask, "Are you in school?"

- If you are working with teenage mothers, maybe you want to ask, "How many children do you have?" But if you are working with a mix, you can ask, "Do you have children?"

- If you are trying to reach a certain geographical range-such as four neighborhoods in one area-you can ask, "Where do you live?"

- If you work with boys and girls, you may want to note if the participant is a boy or girl. In an all-girls program, clearly you wouldn't need to note this.

Step 2. Create a simple questionnaire that captures all the critical information that you would like to gather (see examples above).

Step 3. Add up the results in a chart (see Coverage Exercise Recording Chart, pg. 13)

Step 4. Summarize what you have learned (see Coverage Exercise Summary Chart, pg. 14) and make program changes accordingly.

\section{How to Access the Too}

To learn more about how to conduct a Coverage Exercise and tips for analysis and use of the results, visit:

http://www.popcouncil.org/uploads/pdfs/CoverageExerciseGuide.pdf. 


\section{Coverage Exercise Recording Chart}

The results of the Coverage Exercise allow staff to learn the characteristics of participants in the program including: boys versus girls, age, school status, and where they live and with whom. You will not learn what level they are in school, if they work, or if they have children. If you want to get different information, you will have to change the characteristics listed in this chart. Remember, you must choose the profile information that is most important for your own program.

\begin{tabular}{|l|l|l|l|l|l|}
\hline & Male/Female & Age & In school/out of school & Neighborhood you live in & Live with one or both parents? \\
\hline 1 & & & & & \\
\hline 2 & & & & & \\
\hline 3 & & & & & \\
\hline 4 & & & & & \\
\hline 5 & & & & & \\
\hline 6 & & & & & \\
\hline 7 & & & & & \\
\hline 8 & & & & & \\
\hline 9 & & & & & \\
\hline 10 & & & & & \\
\hline 11 & & & & & \\
\hline 12 & & & & & \\
\hline 13 & & & & & \\
\hline 14 & & & & & \\
\hline 15 & & & & & \\
\hline 16 & & & & & \\
\hline 17 & & & & & \\
\hline 18 & & & & & \\
\hline
\end{tabular}




\section{Coverage Exercise Summary Chart}

This table is used to summarize the information collected with the Coverage Exercise Recording Chart (pg 13).

\begin{tabular}{|c|c|c|c|c|c|c|c|c|}
\hline & \multicolumn{2}{|c|}{ Schooling status } & \multicolumn{2}{|c|}{ Living status } & \multicolumn{4}{|c|}{ Location* } \\
\hline & In School & $\begin{array}{l}\text { Out of } \\
\text { School }\end{array}$ & $\begin{array}{l}\text { One or both } \\
\text { parents }\end{array}$ & Neither parent & Area 1 & Area 2 & Area 3 & Area 4 \\
\hline Girls 10-14 & & & & & & & & \\
\hline Girls 15-19 & & & & & & & & \\
\hline Girls 20+ & & & & & & & & \\
\hline Boys 10-14 & & & & & & & & \\
\hline Boys 15-19 & & & & & & & & \\
\hline Boys 20+ & & & & & & & & \\
\hline
\end{tabular}

*Specify this based on the area where you are working. 

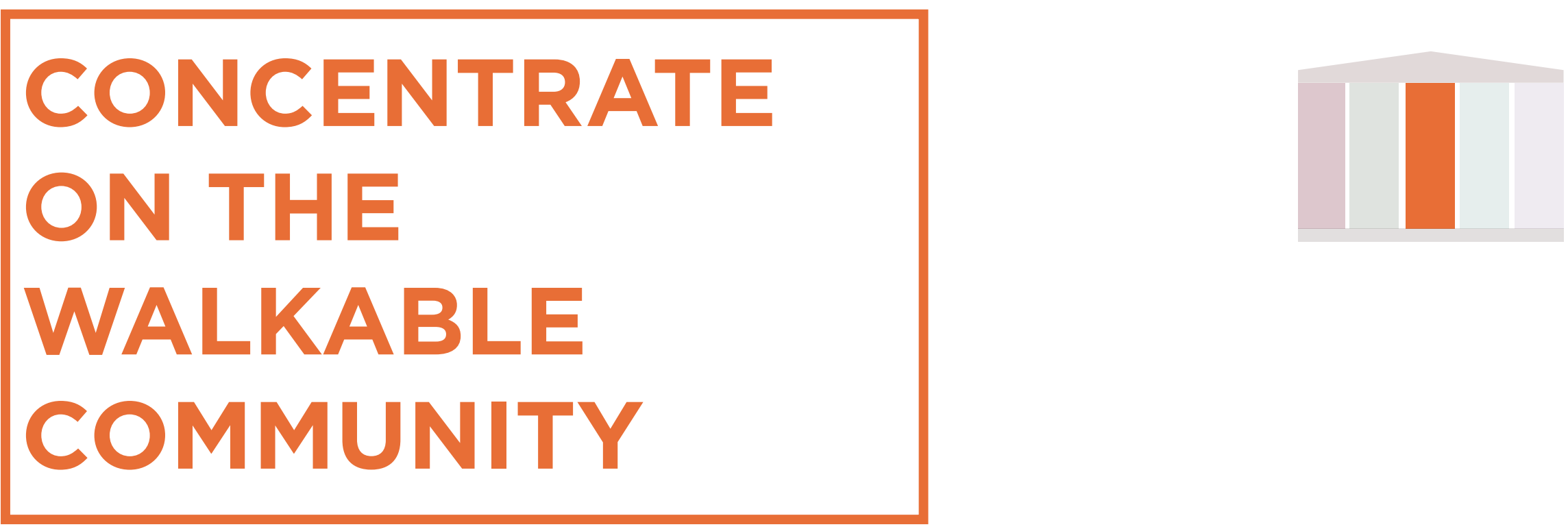

Tool
Community
Resource Scan
What resources and hazards
exist in the community?
pg. 16

ToOL
Community Mapping
Exercise
How do girls judge their
safety and access to
resources in the community?
pg. 19

\begin{tabular}{|} 
TOOL \\
Venn Diagrams of \\
Institutional Access \\
What are girls' perceptions \\
of the organizations or \\
groups in their community? \\
$\qquad p g .22$ \\
\hline
\end{tabular}

To understand girls' and young women's circumstances, program staff need to concentrate on the access that girls and young women have to resources within their "walkable" community-the resources and structures they can reach that define their personal safety and allow them to take action. 


\section{Community Resource Scan}

The Community Resource Scan is a program tool that provides a rapid picture of the geographic and social features of girls' communities. With the tool, program staff can systematically explore a program's catchment area by exploring the area by foot while recording basic features and key resources, using either pen and paper or a mobile phone application. The program tool is intended to provide an informative map of the community but not a detailed inventory. The Community Resource Scan can be used in combination with the Girl Roster tool (pg. 4) to provide informative mapping of where girls live in relation to the resources around them.

The value of the Community Resource Scan is that it can inform program staff decisions about where to locate girl platforms, what community resources exist, and how to connect girls with the resources they need.

\section{Case Study}

This map depicts the results of a Community Resource Scan, a joint exercise of the Salone Girls Network and Plan International in Sierra Leone, led in part by Chernor Bah. All physical assets in the community are included on the map. A ranking of the assets from 1 to 5 according to the girls' level of access was conducted using the categories on pg. 17. The initial mapping of the Kabantana community took approximately two hours in partnership with a local leader. In the process of mapping the community, program staff were able to identify a range of community resources as pinned in the map.

Seeking a location for the girls program, program staff were initially offered an old clinic that was no longer in use. During the course of the mapping, the group identified an unused secondary school that was more appropriate. Local leaders who had been included in the mapping process committed to allowing the program to use this school as a program setting.

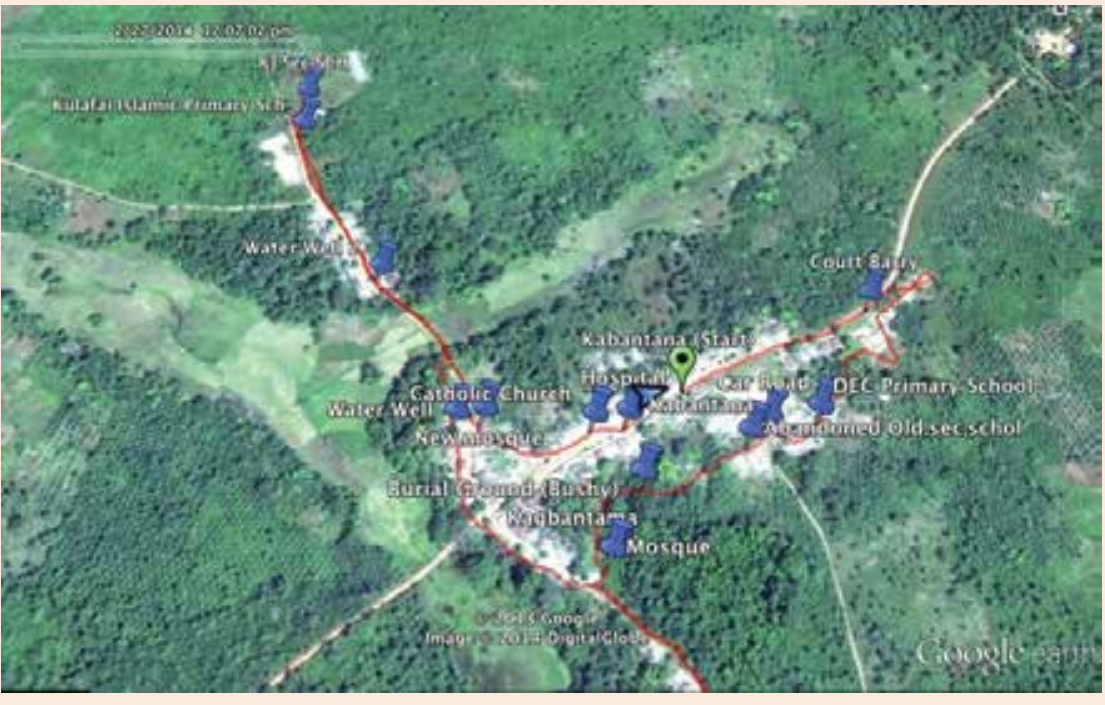

Rural community in Sierra Leone. Population Council, 2014. Plan International. 
You will need an Android Phone with GPS capabilities, an Internet connection, and a Google account.

Step 1. Download a GPS tracking application to your Android phone. Options include: Track My Trip, Geo Tracker (two applications by the same name), GPS Tracker. Make sure the application is linked with your Gmail account.

Step 2. Using your tracking application, "drop a pin" to mark your location and begin by walking the perimeter of the program catchment area, which is based on girls' walkable community (typically 3-4 kilometers, or 2-2.5 miles), the space that girls can safely access. This may correspond with administrative boundaries such as villages, or you may need to divide larger communities into two or more program catchment areas. This step should be conducted in collaboration with key community members such as community leaders, health workers, or others, including adolescent girls themselves.

Step 3. After establishing the boundary, walk systematically through the community to ensure that you have full coverage of the area; then log existing resources in the tracking application. These include community resources such as markets, health posts, schools, or religious institutions; social spaces, such as gathering spots or safe and unsafe places for girls; geographic markers such as reservoirs, or infrastructure such as railroads or highways. In addition to marking existing resources, you can note separately:

- gaps in resources or useful resources that are missing in the community

- hazards to girls' safety or well-being (e.g., areas in which men hang out, where there is little infrastructure, etc.)

You may also want to invite community leaders or other members to hand draw maps of the community boundaries, key characteristics, and resources. For this, the emphasis should be on identifying the basic features of the community that are relevant to girls.

Step 4. You can also note basic information about the resource in the description section of your tracking application, particularly conditions that are relevant to girls. For instance, if you visit a market, it is important to note what time of day you are visiting, the hours of operation of banks or health clinics, and whether there are groups of men or women and girls present. Locating community resources allows partners to identify the range of resources already available in the community, which resources to link to which segments of girls, and how to effectively link girls to the appropriate resources. This exercise also allows program staff to identify gaps in resources, where additional programming is needed, unsafe spaces for girls, and potential girl platforms.

Step 5. Once you have returned to the office, you can use the Community Oval Worksheet (pg. 18) to involve program staff in analyzing information about the resources you mapped. First:

a) Fill in the name of your various girl segments of focus; use the space below each segment name to provide as much detail as possible about that segment.

b) Fill in the name of the various resources you marked during the Community Resource Scan using blank resource circles to name additional resources not already included in the worksheet.

c) Using a scale of 1 to 5,1 signifying the lowest access and 5 signifying the highest access, identify where the resource falls per segment. For example, a girl 10-to-14 years old and in school might not have highest access to HIV testing.

1. Due to cultural and/or social restrictions, girls are likely not found here.

2. This place could serve girls but is not currently doing so.

3. This facility is female-centered, but mostly for adults.

4. There is some time or space for youth, but not necessarily just for girls.

5. Girls are definitely found here and have a safe space at this location.

d) Draw a line from the segment to each of the resources with a number on the scale above next to each line. You can even use a dashed line or solid line to signify the difference in access (dashed being low, solid being high).

\section{How to Access the Tool}

To access more detailed instructions on the Community Resource Scan and assistance for using it, email: girlroster@popcouncil.org. 


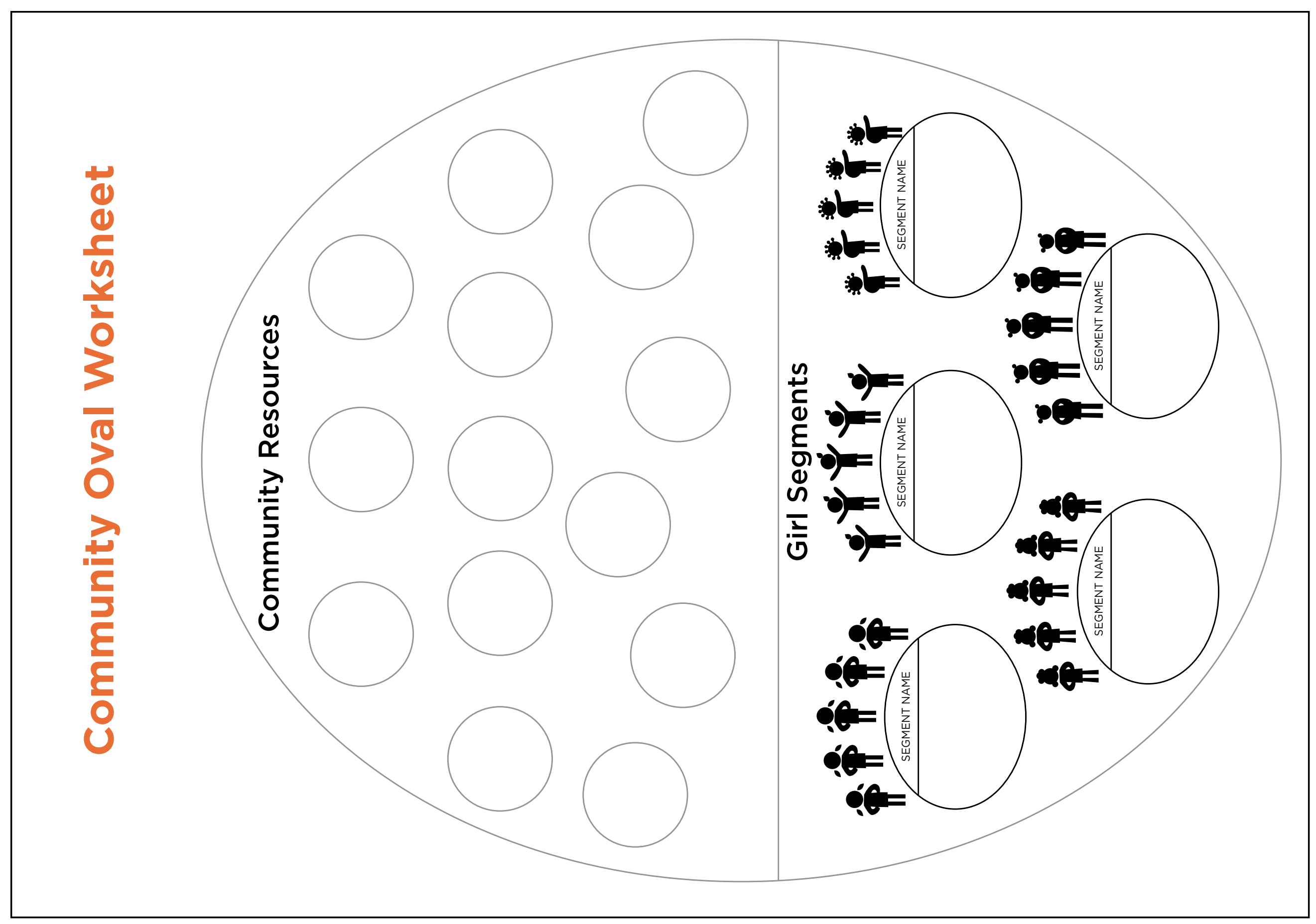




\section{Community Mapping Exercise}

Community maps are important tools to increase understanding of where girls can and cannot go in the program community.,8 This Community Mapping Exercise (Hallman 2016) is the first tool of the GPAQT (see "Tips for Working Directly with Girls", page vii) and is intended to be used within girls' groups with direct participation from the girls themselves. It helps girls identify key community resources as well as areas that may be problematic or unsafe.

By identifying girl-specific structural barriers and access, program staff can build on existent linkages and trust with local service providers and spaces identified as safe, while also seeking reforms to access points that girls should be able to utilize but are deemed unsafe. After creating each map in the Exercise, facilitators can lead a discussion about the places in the community where the girls can and cannot go and record the reasons why. This exercise sheds light on girls' daily experiences and identifies potential obstacles to their safety, participation in a group, and access to services. It is useful to highlight the areas of frequent, occasional, rare, and no access by the girls, as well as areas that may be unsafe or are perceived as unsafe, and the reasons for girls' perceptions.

It is helpful for facilitators to consider how the group views the community. For example, do they all live within the same small village, or do they all live within one neighborhood of a larger town or city? If they come from different areas, they can map the area surrounding the location where their girl groups meet.
It is important to compare the responses between groups of girls who complete the mapping within segments (such as 10-14, 15-19, 20-24-yearolds) to understand differences in their perceptions of the community and access to areas and services. Grouping by age is informative about how perspectives on the community differ by age, and will be important if girls of different ages are participating.

Often one person will dominate the group, so the facilitator should assist by encouraging all girls to participate. If there is more than one group of girls creating maps at the same time, facilitators should make sure they can work with all the groups or have someone trustworthy there to assist. Let the girls know that this is a collective exercise designed to help them communicate their experiences. Some girls will interpret certain locations differently than others; this is perfectly acceptable and it is the facilitator's job to help them find an acceptable solution. Some girls will feel a certain location is safe while others feel it is unsafe; this is also okay. 
You will need large sheets of paper, such as flip charts or butcher paper (one sheet per map), writing utensils (several colored markers, crayons, or pencils), and a large smooth table or floor space.

Step 1. Dividing the girls into smaller groups and preparing the map.

Divide girls into small groups of 5 to 8 individuals according to age (10-14, 15-19, 20-24). Explain that they will be drawing a map of their community and provide background on the purpose of the exercise, focusing on the fact that they will be using the map to identify places where they do and do not go and those that are safe and unsafe. Instruct them to begin by thinking of a central reference point, such as a main road, marketplace, or the group meeting place. If the girls are having a hard time deciding on a central reference point, have them brainstorm a number of possibilities and write them on the flip chart.

Step 2. Drawing the map.

Ask each small group to start at the central reference point and then begin drawing all of the major places they know (schools, religious buildings, markets, bars, shops, clinics, bus stops, railroad tracks, roads, recreational areas, police stations).

Step 3. Identifying spaces in the community where girls visit.

To understand how the girls move about the community, ask them to place a heart next to places where they spend the most time, a triangle next to places where they spend some time, a square next to places they rarely go, and an $X$ next to places they never go. To assist the girls, draw the shapes and their meaning on a chalkboard or flip chart so they are visible during the mapping exercise.

\begin{tabular}{|l|l|c|l|}
\hline$\bigotimes$ & $\begin{array}{l}\text { Heart: Spend most time at } \\
\text { this place }\end{array}$ & $\square$ & Square: Rarely go here \\
\hline & $\begin{array}{l}\text { Triangle: Spend some time } \\
\text { at this place }\end{array}$ & $\chi$ & x: Do not go here \\
\hline
\end{tabular}

Step 4. Exploring unsafe places.

To assist the girls in identifying and discussing the places in their communities that may be unsafe, ask them to draw a circle around the places they feel are unsafe. Then instruct them to rank each of the unsafe spaces by writing a number 1 through 5 next to each circle where 1 is unsafe and 5 is extremely unsafe. If a space is safe, they can leave it marked with only the shapes from Step 3.

Step 5. Exploring the spaces where girls go and do not go.

Display the finished maps by taping them to the wall, chalkboard, or some other visible space. Have a representative from each group present their map and discuss all of the places they included and why.

Step 6. Recreate the Facilitator's Recording of Map Features Grid.

While the girls are finishing up the maps, recreate and post a large version of the table from the Facilitator's Recording of Map Features Grid (pg. 21). As the girls present the places they go and do not go, record them on the table, checking off the appropriate box and noting the reasons for going or not going.

\section{Step 7. Discussion.}

Using the completed Facilitator's Recording of Map Features Grid, initiate a discussion about the places in the community where girls cannot go and why they cannot go there. Explore the reasons that they do and do not go to different places: Is it unsafe? Do their parents or guardians forbid them from going there? Is it too far from home? Do they have to go through an unsafe area to get there? For each location on the map, ask the girls the reason why they do or do not go there and record this in the facilitator's chart. For each place on the map, be sure to do the following:

a) Write the name of the place.

b) Check the box to identify how often they go there.

c) Write the safety ranking number (1-5) for those places that were circled as unsafe and a $\mathrm{O}$ for those places considered safe.

d) Note the reason for rating each place.

Step 8. Ensure that all Community Map Features are recorded.

When the exercise is finished be sure that the Facilitator's Recording of Map Features Grid is completely filled out. If there is any missing information, ask participants to assist you in filling it out before they leave. 


\section{Facilitator's Recording of Map Features Grid}

Directions: List each place shown on the map, how often girls go to that place, why they do or do not go to that place, and why they consider it safe or unsafe.

Country: Region/State: Community:

Facilitator's name: Date: _o (d) $/$ (mm) / _ ( $(\mathrm{m} v)$

Age of girls in this exercise: _. vears) to _vears)

\begin{tabular}{|c|c|c|c|c|c|c|c|}
\hline \multirow[b]{2}{*}{ PLACE } & Most & Some & Rarely & Never & \multirow{2}{*}{$\begin{array}{l}\text { Safety of Place } \\
\text { Rank 1-5 } \\
\text { (write } 0 \text { if } \\
\text { it is safe) }\end{array}$} & \multirow[b]{2}{*}{$\begin{array}{l}\text { Reasons for going or not going } \\
\text { to this place }\end{array}$} & \multirow[b]{2}{*}{$\begin{array}{l}\text { Reasons this place is safe } \\
\text { or unsafe }\end{array}$} \\
\hline & \multicolumn{4}{|c|}{$\triangle_{\text {(Tick the one that applies) }} \square$} & & & \\
\hline & & & & & & & \\
\hline & & & & & & & \\
\hline & & & & & & & \\
\hline & & & & & & & \\
\hline & & & & & & & \\
\hline & & & & & & & \\
\hline & & & & & & & \\
\hline & & & & & & & \\
\hline & & & & & & & \\
\hline & & & & & & & \\
\hline & & & & & & & \\
\hline & & & & & & & \\
\hline
\end{tabular}




\section{Venn Diagrams of Institutional Access}

Venn Diagrams of Institutional Access (Hallman 2016) are an important tool for identifying and classifying information, which in this case is girls' perceptions of the roles of different organizations and groups within the community. ${ }^{9}$ This is the second tool in the GPAQT. Again it is meant to be used in girls' groups with the girls' active participation. Venn Diagrams illustrate relationships between and among groups. This exercise uses Venn Diagrams to identify local organizations, institutions, and groups, such as schools; the church, mosque, or other religious institutions; health clinics; nonprofit organizations and community-based organizations; local government; community groups; youth groups; marketplace; and local businesses, and their relative importance in the lives of girls as reported by your group.

The exercise explores girls' perceptions of the influence of organizations in their lives and girls' trust in and access to these organizations. By exploring these relationships, facilitators gain a greater understanding of the daily experiences of local segments of girls. This may include things that affect how and when they come to this organization, spend time with friends, engage in recreational activities, access services and information, and the type and quality of the information they receive, among other things.

Often one person will dominate the group; facilitators should assist by encouraging all the girls to participate. Let them know that this is a collective exercise designed to help them communicate their experiences. Some girls will interpret certain organizations differently than others; this is perfectly acceptable and it is the facilitator's job to help the girls discuss and find the best way to represent this on the Venn Diagrams. The facilitator must be able to work with all the groups or have someone trustworthy to assist.

\section{How to Use the Tool}

You will need large sheets of paper, such as flip charts or butcher paper (one sheet per map), writing utensils (several colored markers, crayons, or pencils), and a large smooth table or floor space.

Step 1. Dividing the girls into smaller groups.

Divide girls into small groups of 5 to 8 participants by age category (10-14, 15-19, 20-24). Explain that they will be creating something called a Venn Diagram and provide background on its use.
Step 2. Identifying the organizations and institutions.

Ask girls to brainstorm the different organizations and groups of actors that are either based in the community or operate there in some way. Ask one girl from the group to write these on a list that everyone can see. Examples may be: schools, churches, mosques, local government bodies, police, recreational facilities, criminals, alcoholics, other informal groups, farmer cooperatives, businesses, health clinics, parent or youth groups, and nonprofit organizations.

Step 3. Exploring influence.

Ask the girls to look at the list of organizations and institutions they made, and think about how each affects local girls like them. It is possible that some groups have no influence at all on girls. Ask girls to signify the level of influence of each organization on girls like them by using a small, medium, or large circle to the right of the organization name. (Example in image below.)

\begin{tabular}{|l|c|l|l|}
\hline Organization & Influence on girls & Girls' trust in & Girl' linkage to \\
\hline Organization 1 & & & \\
\hline Organization 2 & & & \\
\hline Organization 3 & & & \\
\hline Organization 4 & & & \\
\hline
\end{tabular}

Step 4. Exploring trust and linkages.

Ask the girls to think about those organizations and institutions they trust the most. Instruct the girls to put a "+" symbol on the circles of those organizations and institutions that signifies how much they trust the organization or institution. They can place a maximum of 2 "+" symbols depending on the level of trust they have.

a) NT signifies No Trust

b) "+" signifies Some Trust

c) "+ +" signifies A Lot of Trust 
Ask the girls to think about those organizations and institutions that they feel they have linkages with or access to. Instruct the girls to use the " $\infty$ " symbol to signify how much they trust the organization or

institution. They can place a maximum of two " $\infty$ " symbols depending on the level of trust they have.
a) NL signifies No Linkage
b) " $\infty$ " signifies Some Linkage
c) " $\infty$ " signifies A Lot of Linkage

Step 5. Recreate the Facilitator's Recording of Venn Diagram Features Grid

While the girls are finishing up the Venn Diagrams, recreate and post a large version of the table from the Facilitator's Recording of Venn Diagram Features Grid (pg. 24). As the girls present the organizations and institutions, record them on the table; during the discussion period, check off the appropriate-sized circle and the Trust and Linkage boxes.

Step 6. Discussion

Ask a representative from each group to present its Venn Diagram. Using the Facilitator's Recording of Venn Diagram Features Grid,

initiate a discussion to get a clearer understanding of the relationships represented on the Venn Diagram. For each circle drawn, ask the girls for the reason for its rating and record this in the Facilitator's Recording of Venn Diagram Features Grid. Be sure to:

a) Write the name of the place.

b) Check the box to mark it as a large, medium, or small circle.

c) Check the box that corresponds to how trusted it is by the girls:

"NT" signifies No Trust

"+" signifies Some Trust

"+ +" signifies A Lot of Trust

d) Check the box that corresponds to what extent girls have

a link to it.

"NL" signifies "No" Linkage

" $\infty$ " signifies "Some" Linkage

" $\infty$ " signifies "A Lot" of Linkage

e) Note the reason for trust and linkage ratings of each group in

the last column of the grid.

Step 7. Ensure all the Venn Diagram features are recorded.

When the exercise is finished and before the girls leave, be sure that the Facilitator's Recording of Venn Diagram Features Grid is completed. Every organization on the Venn diagram should be listed, along with its circle size, Trust, and Linkage. 


\section{Facilitator's Recording of Venn Diagram Features Grid}

Directions: List each organization shown on the venn diagram. Record the size of the circle and how it was rated regarding Trust and Link.

Country: Region/State: Community:

Facilitator's name: Date:

Age of girls in this exercise: (years) to (years)

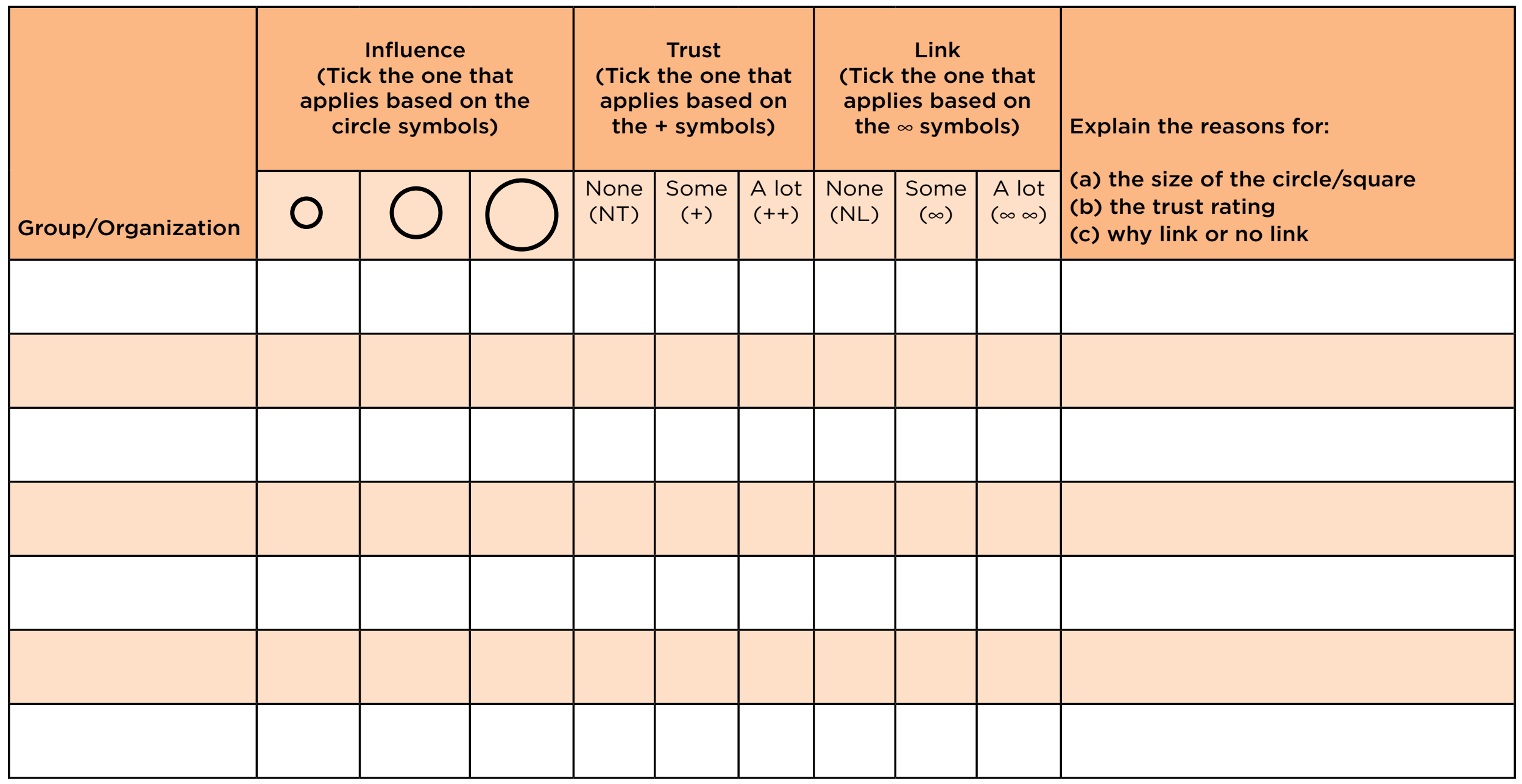



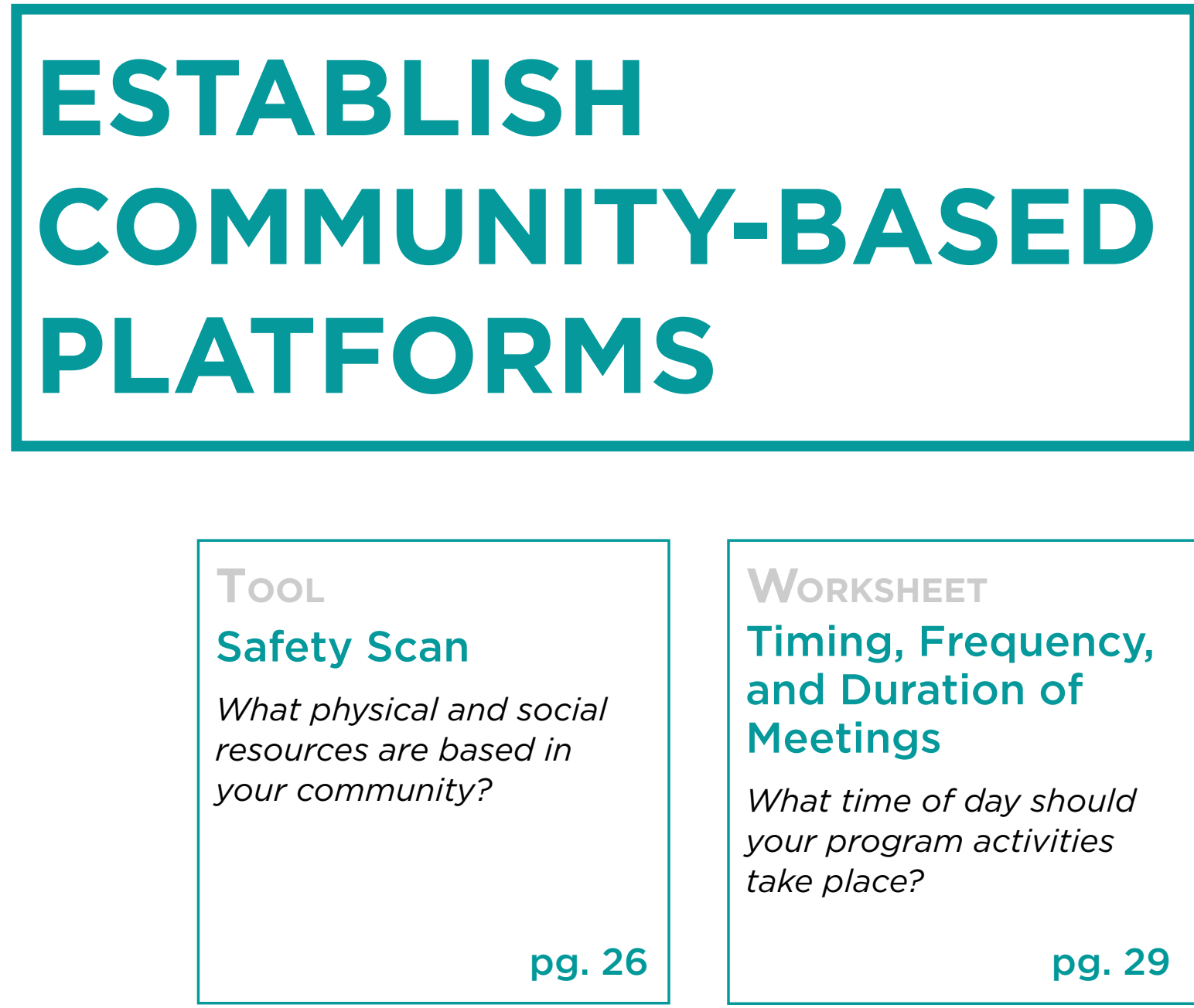

\begin{tabular}{|l|}
\hline WORKSHEET \\
Timing, Frequency, \\
and Duration of \\
Meetings \\
What time of day should \\
your program activities \\
take place? \\
pg. 29 \\
\hline
\end{tabular}

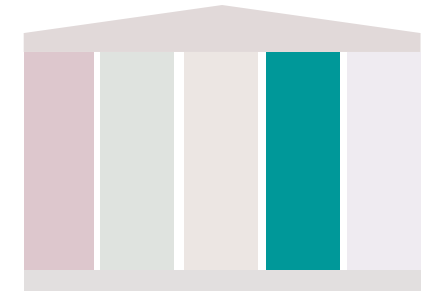

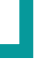




\section{Safety Scan Tool}

The Safety Scan Tool (Austrian and Ghati 2010) helps program staff understand the times, conditions, and situations in which girls feel safe or unsafe. Depending on the goal of the program, these tools can be used in a research style where staff or interviewers sit with girls individually and ask them questions to generate information that is then compiled by the staff. Alternatively, the tool can be used in a participatory fashion where girls fill out tool worksheets themselves.

This tool can be used as a discussion starter with girls or to learn about challenges the program should tackle. It can be used in combination with the Community Resource Scan (pg. 16) and

Coverage Exercise (pg. 11) to enable girls to connect their perceptions of safety to the location of community resources.

\section{How to Use the Tool}

The tool is made of worksheets that implementers can select to explore safety in different domains, such as:

1. Time of day: Allows girls to identify where they are throughout the day and in which of those places they face potentially unsafe situations.

2. Day: Identifies girls' feelings of safety over the different days of the week. This can also help you decide which days would be most strategic for holding program activities.

3. Season: Identifies particularly unsafe times for girls during the year. You might want to adjust your programming to help protect girls during unsafe seasons. For example, if holidays are an unsafe time, be sure to plan activities during that period so that girls are not left alone and vulnerable.

4. Different places in the community: Allows girls to assess the safety of the different places in their community and their degree of safety.

5. Accessing services and opportunities: Identifies common situations that girls find themselves in and allows them to identify which are unsafe. You can use this information to help girls develop safety strategies when engaging in the more unsafe activities (for example, waiting for a bus). (See "Safety Accessing Services and Opportunities" chart, pg. 27)

\section{For More Information}

For more information, please read "Violence Against Adolescent Girls: A Fundamental Challenge to Meaningful Equality" by Judith Bruce http://www.popcouncil.org/uploads/pdfs/2012PGY_GirlsFirst_Violence.pdf

6. Situation: Allows girls to identify certain situations (such as being stopped by a police officer) that makes them feel safe or unsafe. You can use the information to help girls develop safety plans for what to do in these situations, or how to avoid the situations altogether, although that is not always possible.

7. Safety nets: Assesses the strength of girls' social networks. It can help to identify gaps that you might want to fill through your program (such as no one to turn to when they have a health problem). (See "Safety Nets" chart, pg.28)

The key steps to implementation are:

Step 1. Identify what domain(s) of safety are a concern for girls in your segment.

Step 2. Use and adapt charts, to document girls' responses.

Step 3. Use results as conversation starters with the girls.

\section{How to Access the Tool}

The Safety Scan tool is supported by worksheets, such as the examples on the next pages. For further detailed instructions visit:

http://www.popcouncil.org/research/girl-centered-program-design-a-toolkitto-develop-strengthen-and-expand-ado. 


\section{Safety Accessing Services and Opportunities}

\begin{tabular}{|l|l|l|l|l|}
\hline Situation & Always safe to use, access & $\begin{array}{l}\text { Sometimes safe } \\
\text { to use, access }\end{array}$ & $\begin{array}{l}\text { Never safe to } \\
\text { use, access }\end{array}$ & What would make it safer? \\
\hline $\begin{array}{l}\text { Taking public } \\
\text { transportation }\end{array}$ & & & & \\
\hline Taking taxis & & & & \\
\hline $\begin{array}{l}\text { Accessing health } \\
\text { services }\end{array}$ & & & & \\
\hline Going to school & & & & \\
\hline Going to the bank & & & & \\
\hline Going to the post office & & & & \\
\hline On a football pitch & & & & \\
\hline At the salon & & & & \\
\hline Church, mosque & & & & \\
\hline Other & & & & \\
\hline
\end{tabular}




\section{Safety Nets}

\begin{tabular}{|c|c|c|c|c|}
\hline In a emergency, do you have... & Yes & No & Not sure & Comment \\
\hline Five nonfamily female friends? & & & & \\
\hline A place to meet female friends at least once a week & & & & \\
\hline $\begin{array}{l}\text { Someone to turn to if you have a sensitive personal } \\
\text { problem-your own or someone else's? }\end{array}$ & & & & \\
\hline Someone from whom you can borrow money? & & & & \\
\hline A safe place to stay for the night? & & & & \\
\hline Someone to turn to if you have a health problem? & & & & \\
\hline Someone to turn to if you have a financial problem? & & & & \\
\hline
\end{tabular}




\section{Timing, Frequency, and Duration of Meetings Worksheet}

When considering your target segments, there are potential days, times, and frequencies that can facilitate regular and easy access to meetings for long enough to make a difference. Consider the options of timing and frequency, below, and the duration of meetings and determine if they are appropriate for your segment and setting.

\begin{tabular}{|c|c|c|c|}
\hline $\begin{array}{l}\text { SEGMENT: } \\
\text { SETTING: }\end{array}$ & \multicolumn{2}{|c|}{$\begin{array}{l}\text { APPROPRIATENESS } \\
\text { Please consider the appropriateness } \\
\text { of the following to your particular } \\
\text { segment: } \\
\therefore \text { VERY ACCESSIBLE } \\
-. \text { SOMEWHAT ACCESSIBLE } \\
- \text { NOT ACCESSIBLE AT ALL }\end{array}$} & Judgment or implications for action \\
\hline $\begin{array}{l}\text { FREQUENCY AND DURATION OF MEETINGS } \\
\text { Group meetings are more effective with regular } \\
\text { attendance over a specific length of time. Meeting } \\
\text { plans should consider the risk profile of girls and } \\
\text { their daily lives. }\end{array}$ & & & \\
\hline Once in public space every few months & & & \\
\hline Weekly, in a private session & & & \\
\hline 10-week short course & & & \\
\hline Once a week, at least, for an entire year & & & \\
\hline Only in high-risk seasons & & & \\
\hline Only in low-risk seasons & & & \\
\hline All year, with up to 8-week breaks & & & \\
\hline All year, with maximum 10-week breaks & & & \\
\hline During school hours & & & \\
\hline Other: & & & \\
\hline
\end{tabular}




\section{Timing, Frequency, and Duration of Meetings Worksheet \\ (continued from previous page)}

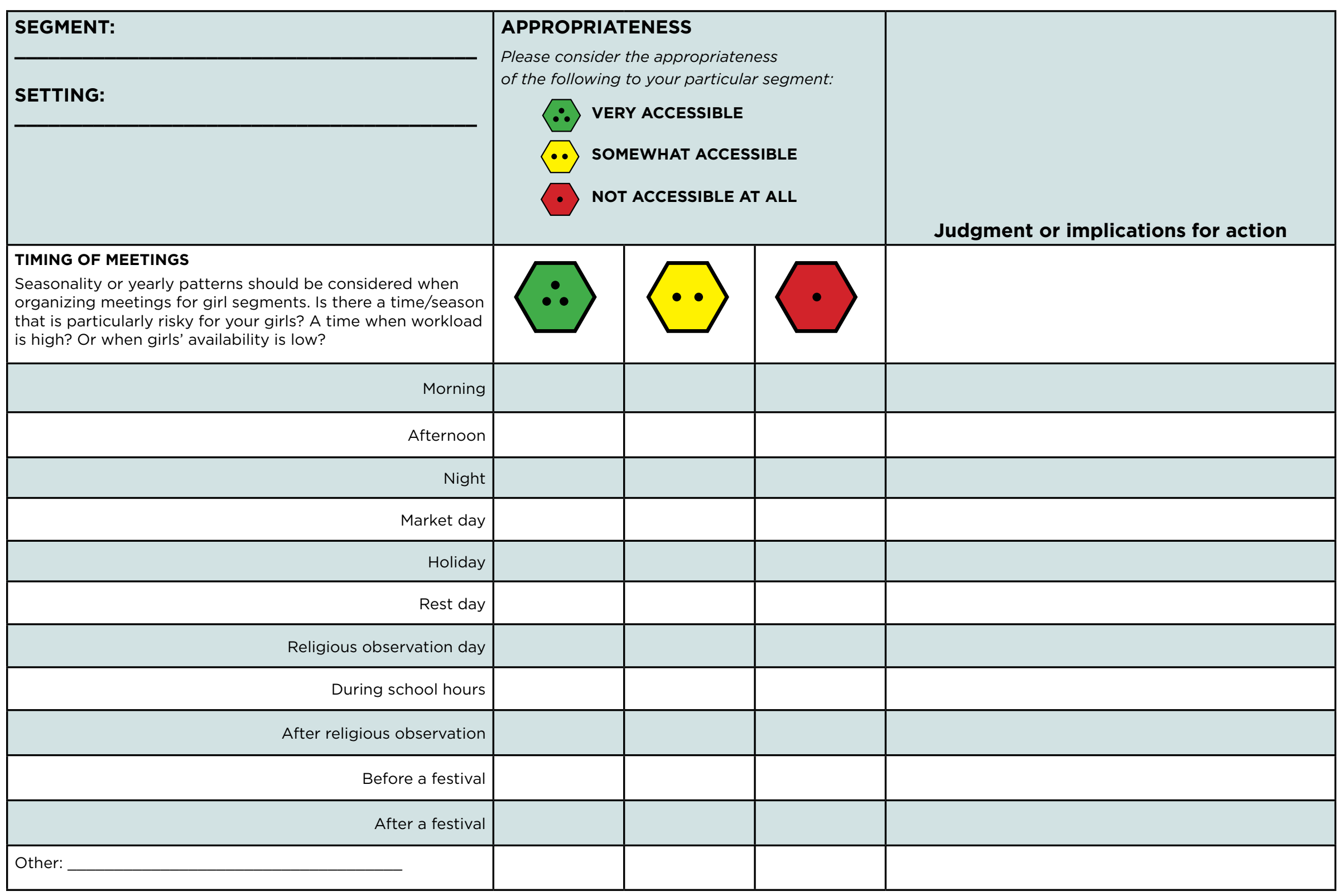




\section{Appropriate Venues Worksheet}

When considering your target segments, the selection of the right venue for your community-based girl platforms is vital to program success. In addition to ensuring the venue is safe, private, and regularly accessible to girls and young women, it also needs to be acceptable to parents and community members. Consider the options of venues and determine their appropriateness given your segment and setting.

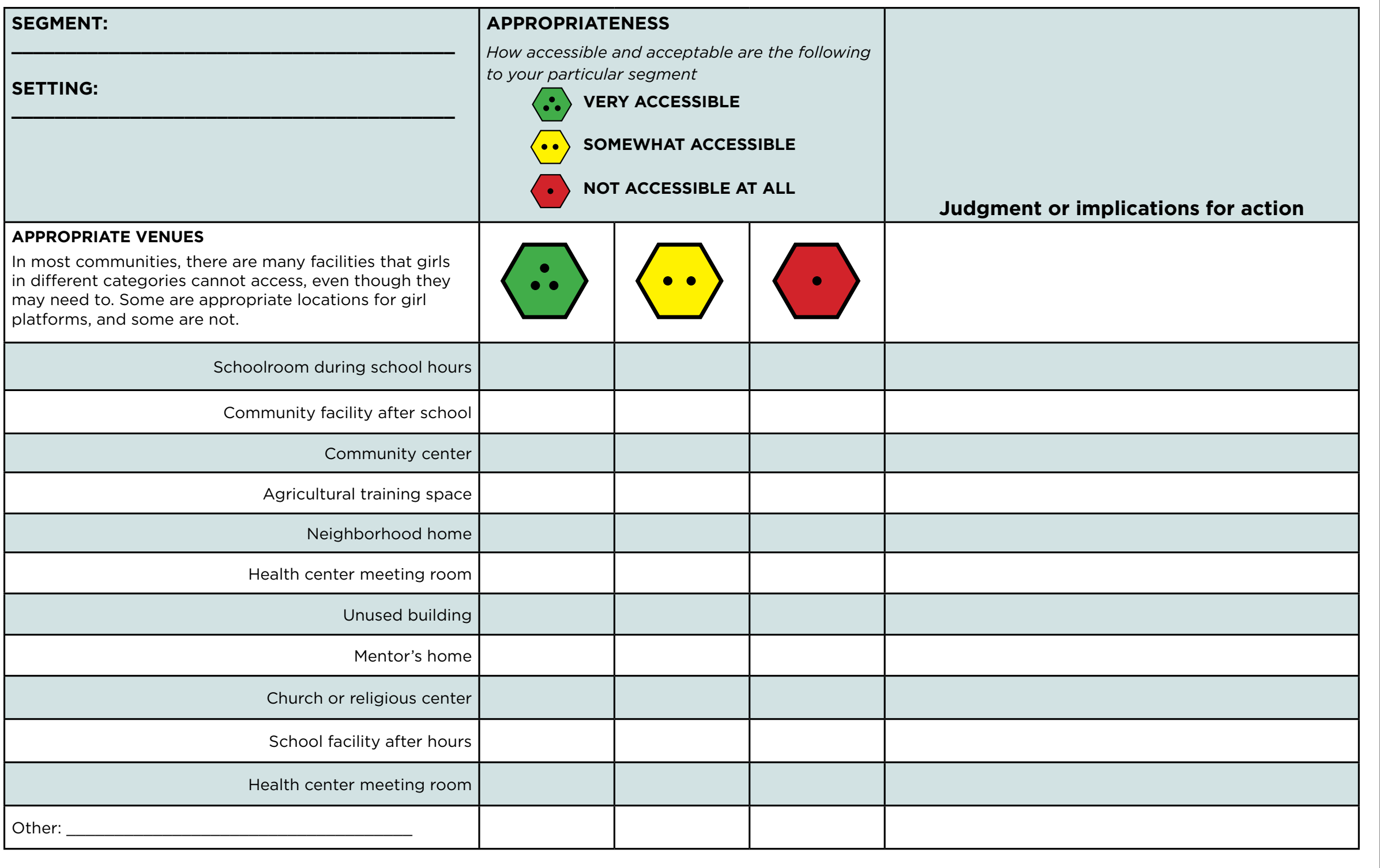




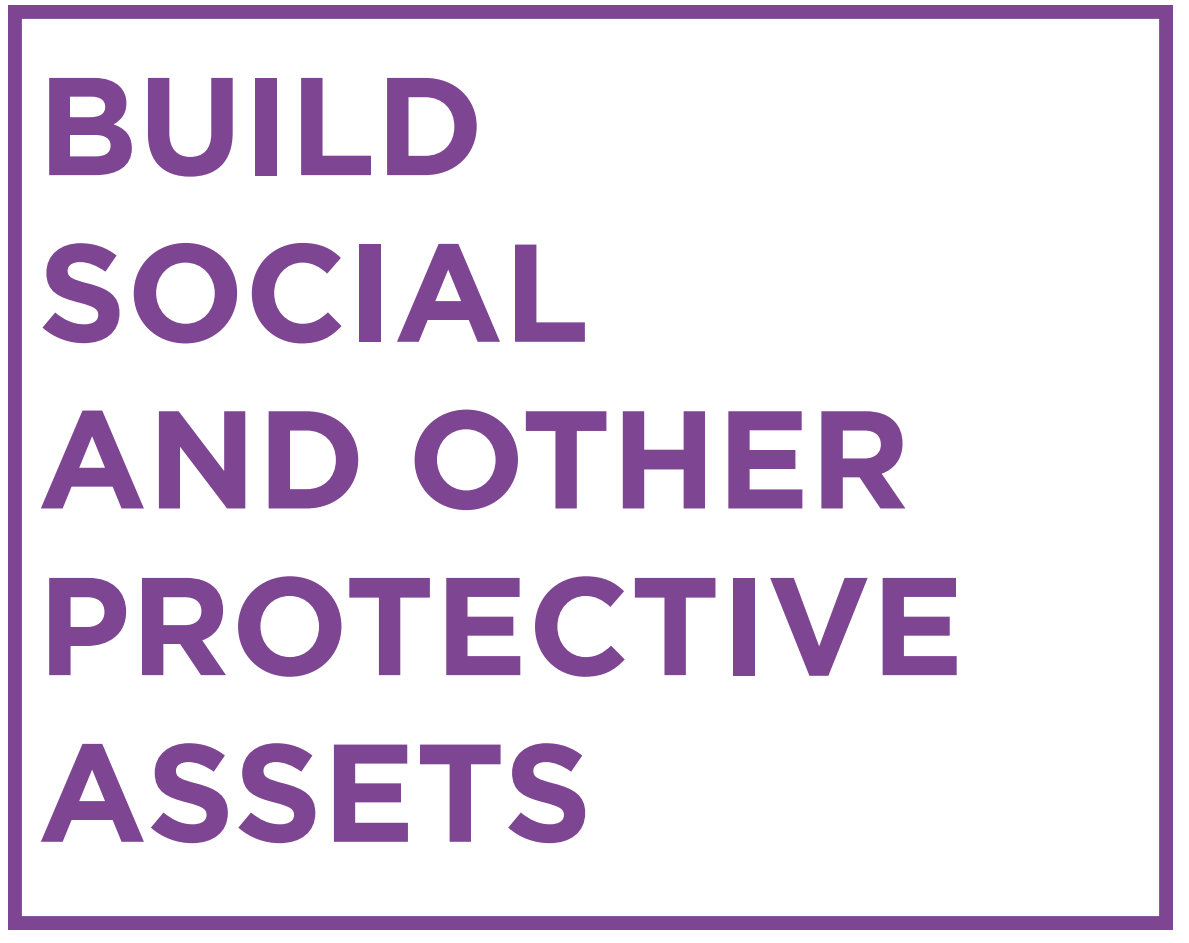

A protective asset is a personal store of value that empowers girls and young women to reduce their risks and expand their opportunities.

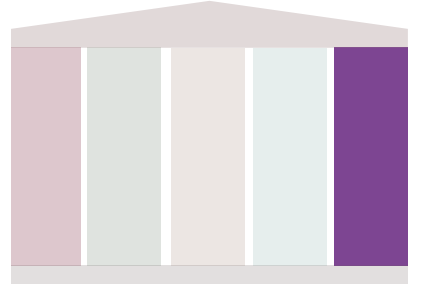

\section{TOOL}

\section{Building}

Assets Toolkit

What do girls need by certain ages in order to thrive?

pg. 34

\section{TOOL}

\section{Social Capital Game}

Who are the important people in girls' lives?

pg. 37

\begin{tabular}{|r|}
\hline WORKSHEET \\
Mentors' Role \\
What should mentors do? \\
pg. 43
\end{tabular}

\begin{tabular}{|} 
WoRKSHEET \\
Turning Protective \\
Assets into \\
Program Content \\
What materials do you \\
need to build assets? \\
pg. 44
\end{tabular}

\section{WORKSHEET}

Defining Achievable Asset Benchmarks

What assets can you build by segment by the end of the program?

pg. 36

TOOL
Ascertaining Sexual
Relationship Types
(ASERT)
Who do girls have sex
with in their community?
pg. 40

\section{WORKSHEET}

Program Planning Summary

What are the key design elements of your program? 


\section{Building Assets Toolkit}

Increasingly, implementing organizations are designing programs specifically targeting adolescent girls. They may use program content that they adapt from material for other audiences and other contexts. This may cover health information but may not address the enabling social, economic, and cognitive skills needed to secure girls' health and rights as well as their wider social and economic opportunities. These skills and opportunities are assets that girls need to make the best use of health information.

An asset is a person's own store of value, which shapes what they can do or be. Assets can be categorized as human/health, social, economic, and cognitive, and can include resources, knowledge, and skills that girls can draw upon to shape their lives and contend with emergencies on their own and others' behalf.

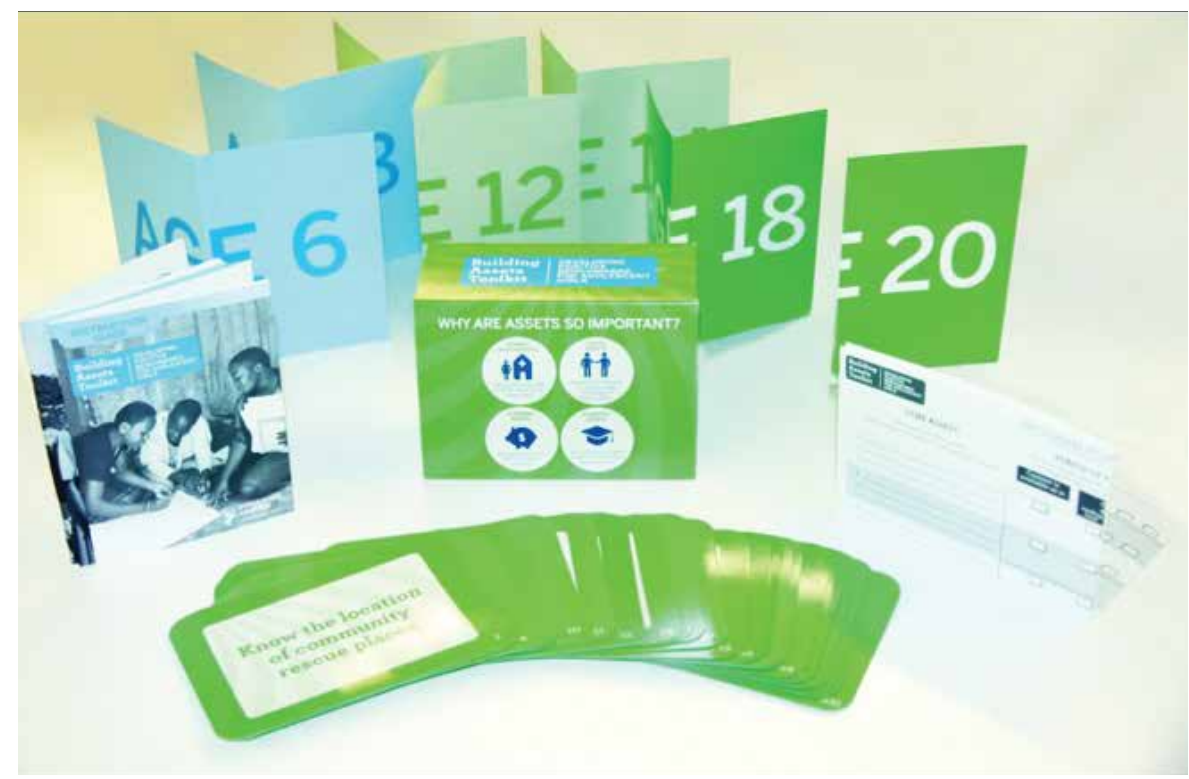

The Building Assets Toolkit
The Population Council's Building Assets Toolkit (Population Council 2015) supports an interactive exercise to identify program activities that build protective assets. The 90-minute asset-building exercise allows multiple stakeholders to use information about girls (e.g., the proportion married by age 15, living apart from parents, out of school, etc.) to think concretely about the appropriate content for their specific target population. For example, among the protective assets that may help girls to avoid HIV are:

1. "Have a safe means of earning money in the formal market." This protective economic asset is important for girls and young women who lack economic security, which can put them in situations that raise the risk of HIV infection. They might engage in sex work or use transactional sex to pay for services they might need such as transportation. In these circumstances, they may not be able to negotiate for condom use, even if they suspect their partner is living with HIV.

2. "Have a place to meet friends safely and privately at least once a week." This protective social asset is important because at around the time of puberty girls often become isolated and lack access to same-sex peers. Friendship networks not only improve safety but also support positive health and other behaviors. In many safe space programs, girls are encouraged to discuss major risks in their lives, find a voice, and gain more power and independence.

Experience with the asset-building exercise demonstrates that in a short time programmers can identify a list of 10 to 15 core and/or desirable assets that girls need at different ages, each of which falls under one of four categories (see box on pg. 35). These assets can serve as the basis for developing program content for different segments of girls-by age, geographic location, marital status, or a combination.

The asset-building exercise lays a foundation for specific and meaningful program content for specific segments of girls that will prepare them to face the challenges of a safe transition to adulthood. 


\section{How to Use the Tool}

To use the Building Assets Toolkit to conduct this exercise, you will first need to tape cards to the floor or wall that designate various age ranges.

(The toolkit is available online or can be recreated with pen and paper.)

Key steps for implementation are:

Step 1. With your group, identify a few assets and invite different participants to model "how to place the asset card." Cards are placed under the latest age or stage at which a girl should have a particular asset.

Step 2. Divide participants into smaller groups and distribute the cards so they can work together.

Step 3. After they have placed their asset cards under the age cards, look at the results and answer the following questions:

a) For the girls you are thinking about, would this asset come early enough?

b) For the girls you are thinking about, does the asset prepare her for risk scenarios and seasons?

c) What is missing?

d) Of the content you now have through age 14, what are core and what are desirable assets? For the core assets identified:

i. Under the current program arrangements, does the content exist and do mechanisms exist to deliver these assets to these girls?

ii. Does your identification of core assets line up with the measures you are using to assess progress?

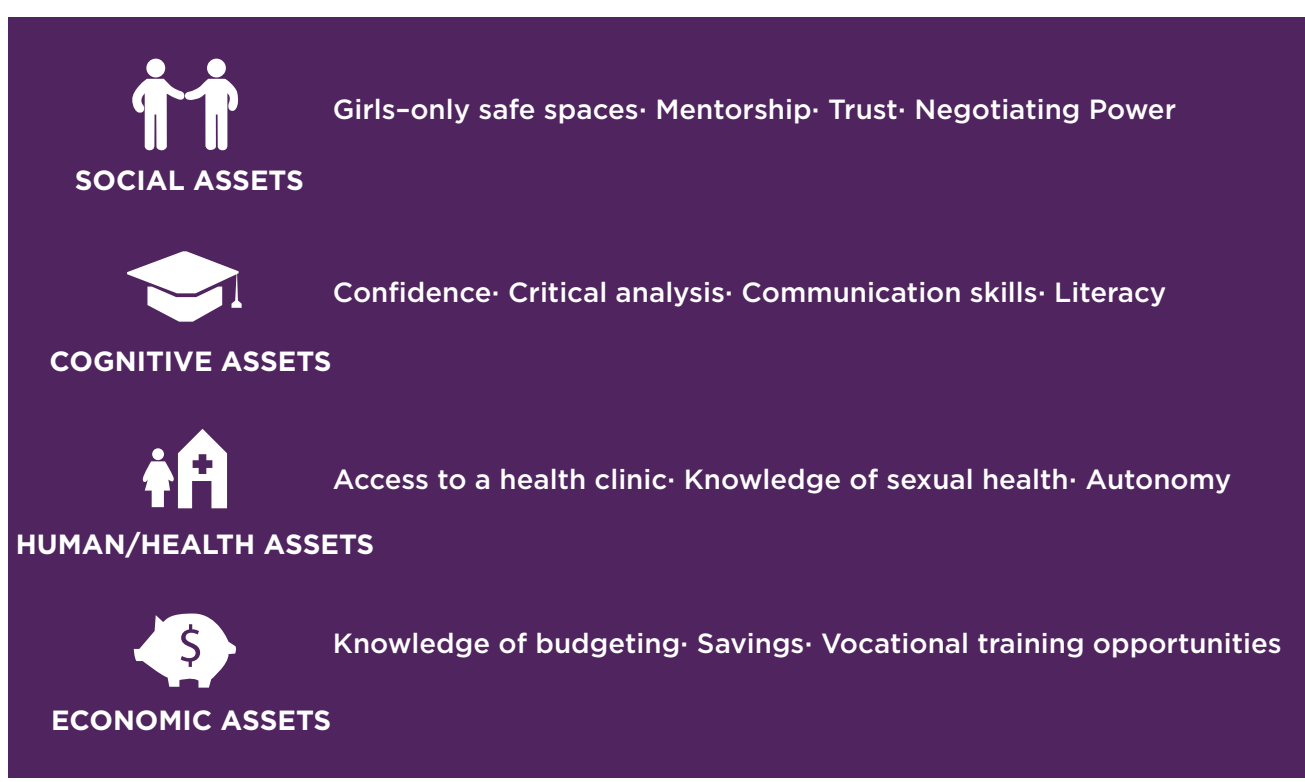

\section{Examples of Social and Other Protective Assets}

\section{How to Access the Tool}

To access the Building Assets Toolkit developed by the Council visit:

http://www.popcouncil.org/research/building-assets-toolkit-developing-positive-benchmarks-for-adolescent-girls.

A downloadable Instruction Guide, Resource Manual, plus 100 asset cards are available. 


\section{Defining Achievable Asset Benchmarks Worksheet}

This worksheet can be useful for program planning and monitoring for a new program, or for an existing program that is changing objectives or content. The worksheet enables program staff to record the specific health, social, economic, and cognitive assets they can realistically expect to measure, by segment and by the end of the program, after a year, or another time period. The specific assets you name represent the changes staff expect to see among the girls who participate regularly enough to receive a specific amount of content-e.g., participating in 80 percent of the sessions-which are benchmarks of the program's success. They provide a basis for monitoring change at the level of the girl from Time 1, the beginning of the program, to Time 2. This girl-level information is an important complement to knowing how many girls attended a session or how many inputs were provided (as described in the Monitor and Evaluate section, pg. 47).

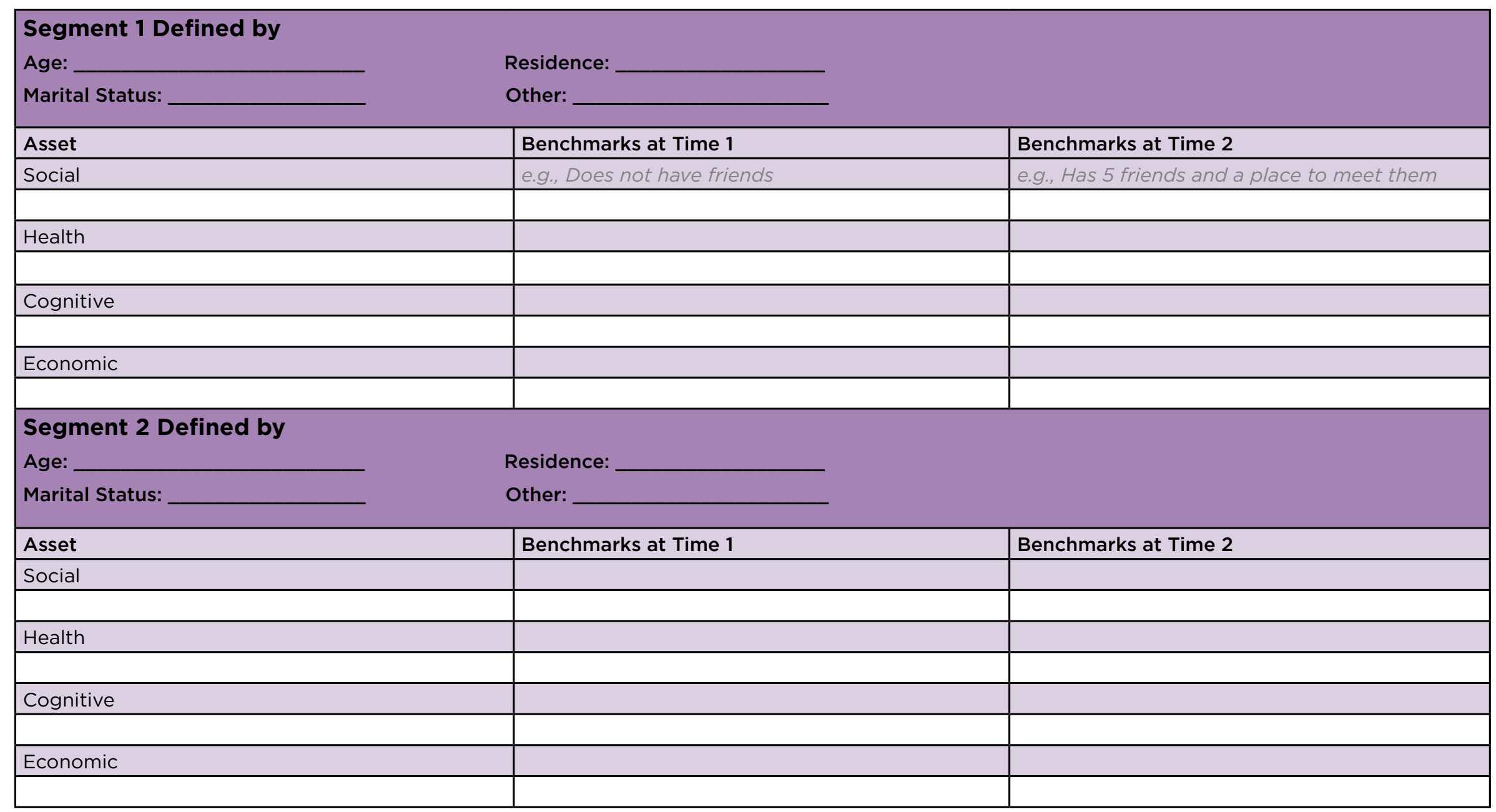




\section{Social Capital Game}

The Social Capital Game (Hallman 2016) is a fun way to examine girls' connections with key figures in their communities and is the third tool in the GPAQT. It enables girls to identify key figures who operate in the community and influence their lives such as political and community leaders, teachers, and parents. The Social Capital Game helps the girls examine which of these key figures is trusted, who is powerful, and with whom they have a link. After completing the game, girls will discuss the nature of their relationships with these key individuals and how their perceptions are similar and different. Exploring these relationships can increase understanding of the daily experiences of girls and can focus programmers' attention on the ways that individuals in girls' communities affect them, both directly and indirectly.

Social capital is based on the nature of relationships or social networks between people, and the trust and reciprocity (or tendency to help each other) that come from those relationships. It focuses on the social networks that exist between us (who knows whom) and the character of those networks, the strength of the relationships within those networks, and how much those networks foster trust."

Important factors related to social capital are trust, power, and linkages. Trust exists in different forms: trust for family and friends differs from trust for a local shop owner who you know is honest. When trust exists, people are willing to do things for one another even without pay or compensation. The power of one person over others also influences the nature of their relationships. Powerful individuals may have considerable influence over girls in the group. The direct access, or linkage, that girls in your group have to these people also affects the strength of their relationship with them. Even when a person does not have a direct link to a figure in the community, she will still either trust or not trust that figure depending on his or her reputation and relationships with others in the community.

Social capital can be a difficult concept to understand. It will be important for the facilitator to ask questions about the girls' social networks and how they trust others within the community. Be sure to discuss how people perceive power and how it can affect us depending on the nature of the relationship we have with the person of power.
Often one girl will dominate the group; encourage all of the girls to participate. Let them know that this is a collective exercise designed to help them communicate their experiences. Let them know that there are no wrong choices or answers for the Social Capital Game and that this is an exercise designed to help them communicate their experiences within the community. Some girls will have different perceptions than others; this is fine and it is the facilitator's job to help the girls find the best way to represent their attitudes during the game. The facilitator should work with all the groups or have someone trustworthy to assist.

\section{How to Use the Tool}

You will need large sheets of paper such as a flip chart or butcher paper (3-4 sheets for your use, for demonstrations); tape; blank cards or sheets of regular (A4) paper that can be cut into squares (10 total squares will be needed); 10 chairs; writing utensils (several colored markers, crayons, or pencils); 18 of the same small object (e.g., coins, index cards, erasers). These objects will represent trust, power, and links during the game. You should have enough to give about 3 of the objects you select to each participant.

NOTE: This exercise requires preparation of special materials. Please be sure to allot yourself enough time to collect, prepare, and distribute the materials before starting the exercise.

Step 1. Introduction to social capital.

Divide girls into small groups of 5 to 8 according to age (10-14, 15-19, 20-24 year olds). Introduce the exercise and explain that:

a) Social capital is based on the nature of relationships or social networks.

b) Trust, power, and linkages are key elements of social capital.

c) When something we do, such as a community improvement project, builds linkages and trust between people, we are also building social capital because we are expanding our social networks and strengthening them. 
Step 2. Identifying key individuals.

Ask the girls: "Who are the key people in this community or who operate in this community?" Choose ten key individuals and write their titles-such as religious leader, teacher, shopkeeper, mayor, police officer-on blank cards. Use titles of the key individuals, not their names. Tape each of these cards to the seat of an empty chair and place the chairs in a circle (or place the cards in 10 different spots on a table). Recreate and post a large format Social Capital Game Features Grid (see pg. 39) on a sheet of paper and write the titles of the ten key individuals in the first column.

Step 3. Hand out three of the social capital objects (e.g., coins, index cards, whatever you have chosen) to each participant. Each round, the same object will represent power, link, and trust respectively. For example, if you have chosen to use coins, each participant should have three coins in their hand. During Step 4, 5, and 6, they will use the same three coins, retrieving them from the chairs after each step is complete.

\section{Step 4. Trust}

a) Discuss with the girls the way they trust some key individuals and do not trust others. It is possible that their views of trustworthiness will vary, which is normal. Ask the girls to walk around the circle of key individuals and think about how much they trust these people. Explain that the three objects in their hand represent trust. They should place the trust objects on the seat of the chair (or on the table) of the key individuals based on how much they trust them. They can give all three objects to one person if they trust him/her very strongly, divide them up among two or three individuals, or not give any out if they do not trust any of the key individuals.

b) When all girls have placed their trust objects, ask a girl to count the number of trust objects each key individual has. Record these numbers in the Trust column on the large format Social Capital Game Features Grid that you created in advance (see pg. 39).

c) Discuss why some key individuals have earned more trust than others. What are the factors that lead to trust or no trust? Record (or have girls record) these reasons on the table. Pick up all the objects and divide them equally among the girls again.

Step 5. Power

a) Discuss the idea of power with the girls. Have them brainstorm about what it means to have power and what it means to not have any power. Have girls walk around the circle of key individuals and think about which have power. Explain that the three objects in their hand now represent power. Instruct them to place the power objects on the seat of the chair (or on the table) of the key individuals based on how much power they have. They can give all three objects to one person if they think that person has a lot of power, divide them up among two or three individuals, or not give any out if they do not feel that any of the key individuals have power.

b) When all girls have placed their power objects, ask a girl to count the number of trust objects each key individual has. Record these numbers in the Power column on a large sheet of paper

c) Discuss why girls perceive that some key individuals have more power than others. What are the factors that give someone power? Record (or have girls record) these reasons on the Facilitator's Recording Grid. Pick up all the objects and divide them among the girls again.

Step 6. Link

a) Discuss the idea of how girls are linked with some people but not with others. Ask for examples of individuals they are linked with and those who they are not linked with. Have the girls walk around the circle of key individuals and think about which of them they are linked with. Explain that the three objects in their hand now represent links. They should place the link objects on the seat of the chair (or on the table) of the key individuals based on how strongly they are linked. They can give all three objects to one person if they think they are strongly linked, divide them up among two or three individuals, or not give any out if they do not feel linked to any of the key individuals.

b) When all girls have placed their link objects, ask a girl to count the number of link objects each key individual has. Record these numbers in the Link column on the same large sheet of paper.

c) Discuss the nature of the links with key individuals. Are there any key individuals with whom they want to build a stronger link? Record (or have girls record) these reasons on the Social Capital Game Feature Grid.

\section{Step 7. Discussion.}

Lead a discussion with the girls about their experiences with this game. Are there any scores that they find surprising? Why are some key individuals more trusted than others? Why are some key individuals more powerful than others? Does being linked or not linked with any of these key individuals have any benefits or cause any difficulties?

Step 8. Recording of Social Capital Game Features.

When the game is finished and the girls have left, be sure to fill out the Social Capital Game Features Grid. Write down in the last column any other important points or issues related to the key individuals that were raised during the game. 


\section{Facilitator's Recording of Social Capital Game Features Grid}

Directions: List each key individual from the Social Capital Game and write the total number of objects they receive for each category. Record the reasons for the count for that individual in the last column.

Country: Region/State:

Community:

Facilitator's name:

Date:

Age of girls in this exercise: _. vears) to_(vears)

\begin{tabular}{|l|l|l|l|l|}
\hline \multirow{2}{*}{ KEY INDIVIDUAL } & \multicolumn{3}{|c|}{ NUMBER OF OBJECTS } & \multirow{2}{*}{ List reasons for trust, power, and link ratings } \\
\cline { 2 - 5 } & Trust & Power & Link & \\
\hline & & & & \\
\hline & & & & \\
\hline & & & & \\
\hline & & & & \\
\hline & & & & \\
\hline & & & & \\
\hline & & & & \\
\hline & & & & \\
\hline
\end{tabular}




\section{Ascertaining Sexual Relationship Types (ASERT ${ }^{\mathrm{TM}}$ )Tool}

The Ascertaining Sexual Relationship Types (ASERT) Tool (Hallman 2016) is the fourth and final tool in the GPAQT. While all the GPAQT tools require active participation of girls, it is not appropriate to conduct ASERT with girls under 14 years old. ASERT facilitates a method of understanding how girls describe and rank people in their community with whom they have sex and the reasons for having sex with each type of person. Through ASERT, a facilitator can create a visual representation of the descriptions of the types of people girls have sex with, and the reasons for these sexual relations. ${ }^{12}$ This can be a powerful exercise because it offers girls an opportunity to think about and discuss issues related to HIV risk, social status, and economic survival strategies. After implementing the ASERT tool, facilitators lead a discussion on the reasons for ranking different partners. By exploring these issues, it is possible to gain understanding of the experiences of local segments of girls.

Because of the sensitive nature of the questions, it is essential that program staff follow the ASERT rules when planning and conducting the exercise:

1. The tool should only be used with girls and young women aged 15-19 or 20-24 years; it should not be used with 10-14-year-old girls.

2. The tool must be used with pre-existing groups of girls who trust each other and feel comfortable expressing their ideas to one another and to their mentors.

3. A safe and private space is absolutely required to conduct the exercise; girls need to feel sure that their responses are confidential and that they are comfortable and safe discussing these topics.

4. It is not acceptable to ask about any individual girl's experience or behavior; the tool is most effective when girls are asked about "girls like you in this community." This provides girls with more anonymity and safety. The goal is to explore their opinions about girls like them in the community, not to report on their own individual behaviors or experiences.

5. Facilitators should identify health and psychosocial services before conducting the exercise in case any girls report experiences of violence or abuse.

6. Facilitators should inform participants that it is okay to describe the exercise to others outside the group, but ask them not to share the details of the results with anyone outside the group.
Note that the ASERT Tool is focused on an extremely sensitive topic that may be challenging for girls who do not want to express their thoughts on the subject. Please emphasize that the exercise is not about each girl's individual experience, nor is it asking them to name or discuss particular individuals. The questions pertain to the average girl in her community, not to her. You must make sure this is clear for all girls.

It is possible that girls of different ages will have different views on the topic. Because of this, it is important to divide the girls into small groups according to age, with all girls in a group being either 15-19 years old or older.

Often one person will dominate the group; facilitators should encourage all girls to participate. Tell them there are no right or wrong answers for the ASERT Tool and that this exercise is designed to help them communicate their views. Girls express their responses in different ways; this is perfectly acceptable. It is the facilitator's job to help girls find the best way to represent their beliefs using the ASERT Tool. The facilitator should work with all the groups or have someone trustworthy to assist. 
You will need large sheets of paper such as a flip chart or butcher paper (at least one sheet per group, plus 3-4 more for you to use for demonstration); additional regular (A4) size sheets of paper (3-4 sheets per group); writing tools (several colored markers, crayons, or pencils); scissors; large smooth table or floor space; tape or glue.

Step 1. Divide the girls into small groups.

Divide into groups of 5-8 girls according to age (15-19, 20-24). Explain that each small group will be conducting something called the ASERT exercise and provide information about its purpose (as described above).

Step 2. Identify the types of people who are sexual partners for girls.

Begin by asking girls to think about all of the different types of people that girls like them have sex with. Remind them that you are not asking about their own sexual experiences, only about those of girls in the community who are similar to them. You can provide them with some examples, such as boyfriend, neighbor, classmate, teacher, older married man, uncle, family friend, police officer, stranger, bartender. Ask them not to use names of specific people in the community. Instruct them to list each of the people they come up with along the top of a large sheet of paper as illustrated below. The girls can name as many types of people as they wish. Use extra sheets of paper to add additional columns.

\begin{tabular}{|l|l|l|l|}
\hline Married Man & Teacher & Boyfriend & Neighbor \\
\hline & & & \\
\hline & & & \\
\hline & & & \\
\hline
\end{tabular}

Step 3. Identify the reasons girls have sex with each partner type.

Ask the girls to think about each type of person identified. Instruct them to list the different reasons that girls like them in their community have sex with this type of person. You can give them examples such as: parents like him; lives close by; he shows love; he gives gifts; he has a car to take a girl places; he has a phone a girl can use; he puts pressures in nonphysical ways; he physically forces; he is not married; he will do a favor; he helps the family.
Step 4. Rank the reasons girls have sex with each type of partner.

Once the girls have gone through each partner type and listed all of the reasons girls have sexual relationships with that type, have them rank the reasons so the most important one is listed first for each type of person. Each reason listed below in the column should be the next most important, with the least important reason last. They should number these reasons 1, 2, 3, 4, and so forth. In the end, the larger sheet will look something like this:

\begin{tabular}{|l|l|l|l|}
\hline Married Man & Boyfriend & Neighbor & Uncle \\
\hline $\begin{array}{l}\text { 1. He gives her } \\
\text { money }\end{array}$ & 1. She loves him & $\begin{array}{l}\text { 1. He buys her } \\
\text { small things }\end{array}$ & $\begin{array}{l}\text { 1. He physically } \\
\text { forces her }\end{array}$ \\
\hline $\begin{array}{l}\text { 2. He does not } \\
\text { interfere with her } \\
\text { life }\end{array}$ & $\begin{array}{l}\text { 2. She can make } \\
\text { plans with him }\end{array}$ & $\begin{array}{l}\text { 2. He threatens to } \\
\text { ruin her reputation if } \\
\text { she says no }\end{array}$ & $\begin{array}{l}\text { 2. She does not } \\
\text { want to report } \\
\text { his acts because } \\
\text { he is family }\end{array}$ \\
\hline 3 He is not jealous & 3. Common interests & $\begin{array}{l}\text { 3. He is always } \\
\text { around }\end{array}$ & $\begin{array}{l}\text { 3. She fears her } \\
\text { father will blame her }\end{array}$ \\
\hline
\end{tabular}

Step 5. Recreate the Facilitator's Recording of ASERT Features Grid. While the girls are doing the exercise, recreate large-format tables from the Facilitator's Recording of ASERT Features Grid for each small group and post them where they are visible. As the girls discuss the different partner types, record them on the table, listing the people girls have sex with in the first column and the reasons they have sex with them, by order of importance, across the row. Record in the last column any important points the girls make about the different types of individuals.

\section{Step 6. Discussion.}

Ask a girl from each small group to present the results of her ASERT exercise. After they complete the presentation, ask if anyone has any questions. Discussion will provide a clearer understanding of the relationships represented in the ASERT Grid. Record any further information in the "Notes" column of the Grid (see Facilitator's Recording of ASERT Features Grid). 


\section{Facilitator's Recording of ASERT TM Features Grid}

Directions: List each key individual who is a sexual partner for the girls and the reasons, ranked, why girls have sex with him.

Country: Region/State: Community:

Facilitator's name:

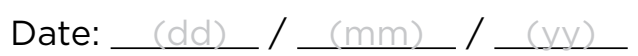

Age of girls in this exercise: _. vears) to_(vears)

\begin{tabular}{|c|c|c|c|c|c|c|}
\hline \multirow[b]{2}{*}{ PARTNER TYPE } & \multicolumn{5}{|c|}{ REASONS FOR HAVING SEX WITH THIS TYPE } & \multirow[b]{2}{*}{$\begin{array}{l}\text { NOTES ABOUT THIS } \\
\text { PARTNER TYPE }\end{array}$} \\
\hline & Most important & $\begin{array}{l}\text { Second most } \\
\text { important }\end{array}$ & $\begin{array}{l}\text { Third most } \\
\text { important }\end{array}$ & $\begin{array}{l}\text { Fourth most } \\
\text { important }\end{array}$ & $\begin{array}{l}\text { Fifth most } \\
\text { important }\end{array}$ & \\
\hline & & & & & & \\
\hline & & & & & & \\
\hline & & & & & & \\
\hline & & & & & & \\
\hline & & & & & & \\
\hline & & & & & & \\
\hline & & & & & & \\
\hline & & & & & & \\
\hline & & & & & & \\
\hline & & & & & & \\
\hline
\end{tabular}




\section{Mentors' Role Worksheet}

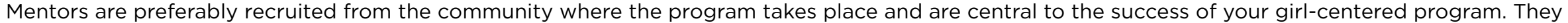

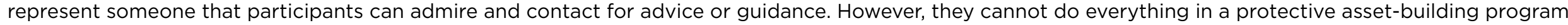

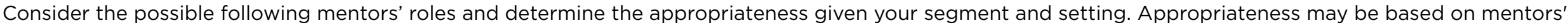

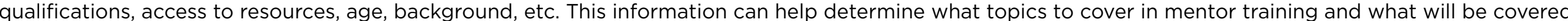
by invited guests. A stipend for mentors is highly recommended.

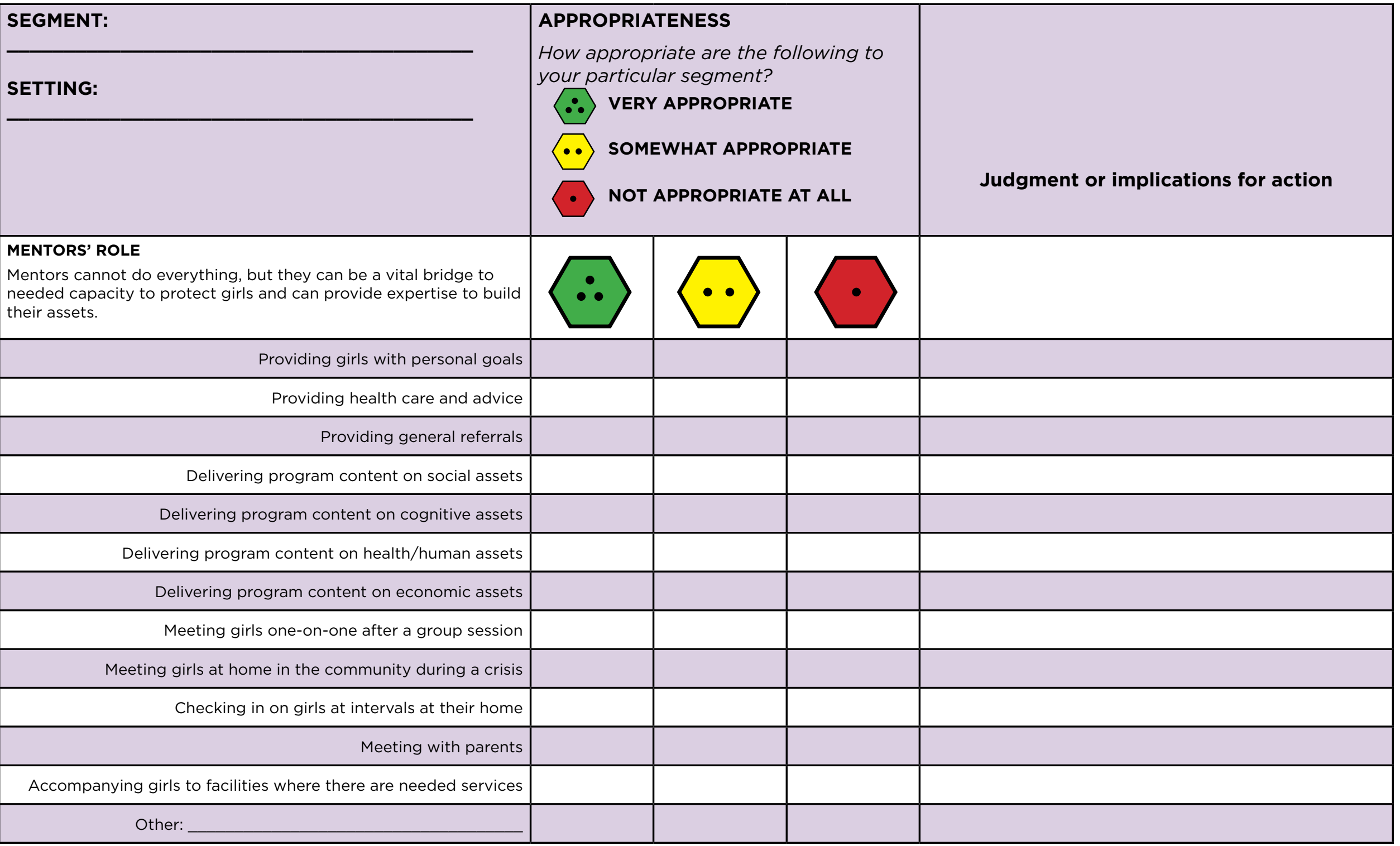




\section{Turning Protective Assets into Program Content Worksheet}

This worksheet can be used to determine what material exists to support your program content, what needs to be adapted or developed, and who can deliver the content. It can be used in combination with the Building Assets Toolkit to consider the assets that your program will build for the target segment of girls and young women. The priority assets are listed in the first column; for each asset, assess and record the availability of material and the appropriate delivery strategy.

\section{SEGMENT:}

\section{SETTING:}

\begin{tabular}{|c|c|c|c|c|c|c|c|}
\hline \multirow{4}{*}{$\begin{array}{l}\text { This worksheet will help } \\
\text { program staff move from } \\
\text { identifying assets to } \\
\text { identifying and delivering } \\
\text { program content }\end{array}$} & \multicolumn{7}{|c|}{ PROGRAM CONTENT } \\
\hline & \multicolumn{3}{|c|}{ STATUS OF PROGRAM CONTENT } & \multicolumn{3}{|c|}{ DELIVERY OF CONTENT } & THINKING AHEAD \\
\hline & \multicolumn{3}{|c|}{ For each asset, record: } & \multicolumn{3}{|c|}{ Who will deliver program content? } & \multirow{2}{*}{$\begin{array}{l}\text { For each asset, provide } \\
\text { additional comments to help you } \\
\text { plan and execute the program in } \\
\text { your context. } \\
\text { This may include ways to engage } \\
\text { families and communities, bearing in } \\
\text { mind that some assets can } \\
\text { create risks for girls that need } \\
\text { to be managed. }\end{array}$} \\
\hline & $\begin{array}{l}\text { Is the content } \\
\text { available } \\
\text { as is? }\end{array}$ & $\begin{array}{l}\text { Does the } \\
\text { content need } \\
\text { adaptation } \\
\text { (reading level, } \\
\text { language, } \\
\text { etc.)? }\end{array}$ & $\begin{array}{l}\text { Does new } \\
\text { material } \\
\text { need to be } \\
\text { developed? }\end{array}$ & A mentor only? & $\begin{array}{l}\text { First a } \\
\text { mentor, then } \\
\text { girl leaders? }\end{array}$ & $\begin{array}{l}\text { Peer-to-peer? } \\
\text { Other? }\end{array}$ & \\
\hline 1 & & & & & & & \\
\hline 2 & & & & & & & \\
\hline 3 & & & & & & & \\
\hline 4 & & & & & & & \\
\hline 5 & & & & & & & \\
\hline 6 & & & & & & & \\
\hline 7 & & & & & & & \\
\hline 8 & & & & & & & \\
\hline
\end{tabular}




\section{Program Planning Summary Worksheet}

This worksheet can be used to specify the different elements of planning that are required when designing a new program or adjusting an existing one-the who, what, and how. Beginning with the priority segment(s) you have identified as the program's target groups, and using the tools and exercises included in the collection, instructions on this worksheet will help you record details in each row for each segment of girls. Additional pages can be used to expand your summary of program plans.

\begin{tabular}{|c|c|c|c|c|c|c|c|}
\hline \multicolumn{4}{|c|}{ WHO? THE RIGHT GIRLS } & \multicolumn{2}{|c|}{$\begin{array}{l}\text { WHAT? THE RIGHT THINGS AT THE } \\
\text { RIGHT TIME IN THE RIGHT PLACES }\end{array}$} & \multirow[t]{2}{*}{$\begin{array}{l}\text { HOW? THE RIGHT } \\
\text { PROGRAM CONTENT }\end{array}$} & \multirow[t]{3}{*}{$\begin{array}{l}\text { WHY? PREDICTED } \\
\text { OUTCOMES }\end{array}$} \\
\hline \multirow{2}{*}{\multicolumn{2}{|c|}{$\begin{array}{l}\text { GIRL AND YOUNG } \\
\text { WOMAN SEGMENT }\end{array}$}} & & & & & & \\
\hline & & $\begin{array}{l}\text { Coverage Goal } \\
\text { Number of girls/young } \\
\text { women in segment } \\
\text { compared to level of } \\
\text { program coverage } \\
\text { desired. (See results } \\
\text { from Girl Roster, pg. 4.) }\end{array}$ & $\begin{array}{l}\text { Recruitment } \\
\text { Approach } \\
\text { Recruitment methods } \\
\text { for priority segment. } \\
\text { (See Recruitment } \\
\text { Strategy Worksheet, } \\
\text { pg. 10.) }\end{array}$ & $\begin{array}{l}\text { Venues and Meetings } \\
\text { Meetings' location, } \\
\text { timing, length, frequency. } \\
\text { (See Timing, Frequency, } \\
\text { and Duration of Meetings } \\
\text { Worksheets, Appropriate } \\
\text { Venues, pgs. 29-31.) }\end{array}$ & $\begin{array}{l}\text { Mentors } \\
\text { Who are mentors, their } \\
\text { roles (see Mentors' Role } \\
\text { Worksheet, pg. 43), } \\
\text { number needed, and } \\
\text { stipend value. Some } \\
\text { mentors can cover } \\
\text { multiple segments. }\end{array}$ & $\begin{array}{l}\text { Core Protective Assets } \\
\text { Describe protective asset(s) needed } \\
\text { to address girl segments' priority } \\
\text { issues (see Building Assets Toolkit, } \\
\text { pg. 34) and program activities } \\
\text { you will conduct to build those } \\
\text { priority assets. }\end{array}$ & \\
\hline \multirow{4}{*}{ A } & \multirow[t]{2}{*}{ SEGMENT: } & \# OF GIRLS: & & LOCATION: & WHO: & \multirow[t]{2}{*}{ ASSETS: } & \\
\hline & & & & TIMING OF MEETINGS: & ROLE: & & \\
\hline & \multirow[t]{2}{*}{$\begin{array}{l}\text { SEGMENT-SPECIFIC } \\
\text { CHALLENGES: }\end{array}$} & \% COVERAGE: & & LENGTH OF MEETINGS: & \# OF MENTORS NEEDED: & \multirow[t]{2}{*}{ ACTIVITIES: } & \\
\hline & & & & $\begin{array}{l}\text { FREQUENCY (\# OF } \\
\text { MEETINGS PER YEAR): }\end{array}$ & STIPEND VALUE & & \\
\hline \multirow{4}{*}{ B } & \multirow[t]{2}{*}{ SEGMENT: } & \multirow[t]{2}{*}{ \# OF GIRLS: } & & LOCATION: & WHO: & \multirow[t]{2}{*}{ ASSETS: } & \\
\hline & & & & TIMING OF MEETINGS: & ROLE: & & \\
\hline & \multirow[t]{2}{*}{$\begin{array}{l}\text { SEGMENT-SPECIFIC } \\
\text { CHALLENGES: }\end{array}$} & \% COVERAGE: & & LENGTH OF MEETINGS: & \# OF MENTORS NEEDED: & \multirow[t]{2}{*}{ ACTIVITIES: } & \\
\hline & & & & $\begin{array}{l}\text { FREQUENCY (\# OF } \\
\text { MEETINGS PER YEAR): }\end{array}$ & STIPEND VALUE & & \\
\hline \multirow{4}{*}{ C } & \multirow[t]{2}{*}{ SEGMENT: } & \# OF GIRLS: & & LOCATION: & WHO: & \multirow[t]{2}{*}{ ASSETS: } & \\
\hline & & & & TIMING OF MEETINGS: & ROLE: & & \\
\hline & \multirow{2}{*}{$\begin{array}{l}\text { SEGMENT-SPECIFIC } \\
\text { CHALLENGES: }\end{array}$} & $\%$ COVERAGE: & & LENGTH OF MEETINGS: & \# OF MENTORS NEEDED: & \multirow[t]{2}{*}{ ACTIVITIES: } & \\
\hline & & & & $\begin{array}{l}\text { FREQUENCY (\# OF } \\
\text { MEETINGS PER YEAR): }\end{array}$ & STIPEND VALUE & & \\
\hline
\end{tabular}



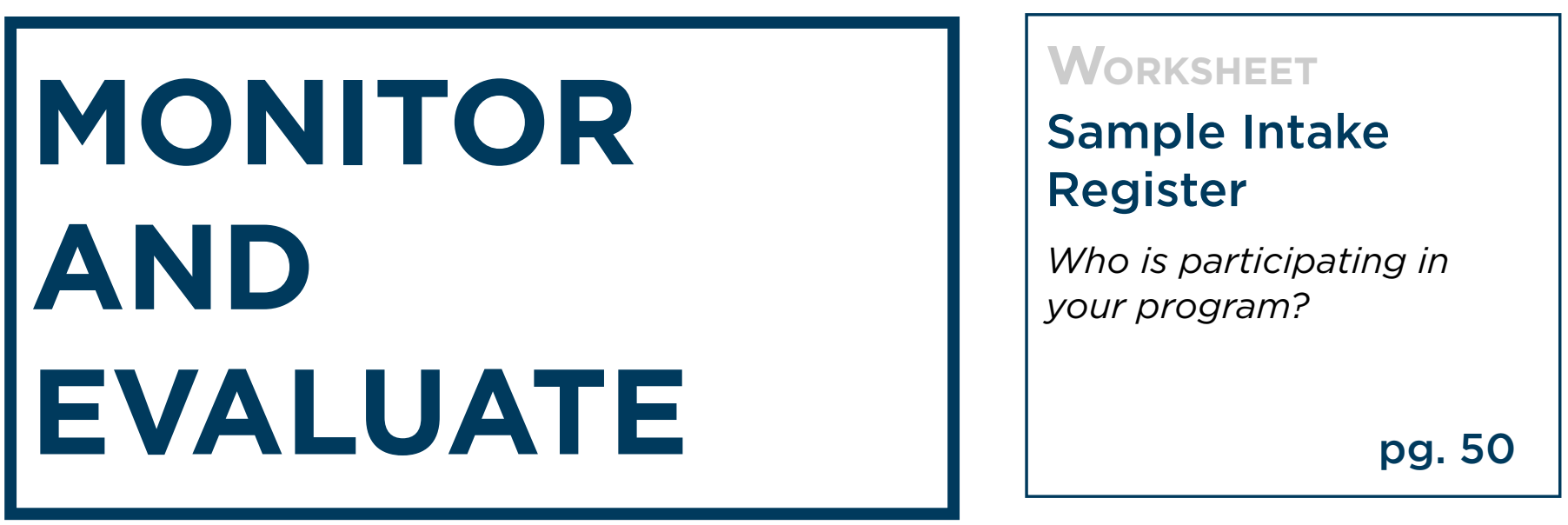

\begin{tabular}{|} 
WORKSHEET \\
Monitoring and \\
Evaluation \\
What should be measured \\
to assess your program's \\
progress and success? \\
pg. 51 \\
\hline
\end{tabular}

\begin{tabular}{|} 
Tool \\
Protective Asset \\
Outcome Indicators \\
How do you measure the \\
progress of your \\
asset-building program? \\
pg. 54
\end{tabular}

Effective monitoring and evaluation can help you track the success of your program, determining whether you have increased your reach using the preceding tools and heightened your impact. 


\section{Monitoring and Evaluation Resources}

Good monitoring and evaluation can help you to chart the success of your program. Monitoring can tell you who you are reaching and what you are doing; evaluation can tell you if your program is making a difference and what kind of changes are taking place in girls and young women as a result of their participation in the program.

Before developing your monitoring and evaluation plans and tools, it is important to consider such questions as:

-Who will create and use the tools; who is responsible for ensuring that they are completed?

- When will the tools be used?

- Who is responsible for the analysis and reporting of the information that the tools are used to collect?

- How often and in what format will the analysis and reporting be done?

The Sample Intake Register and Monitoring and Evaluation Worksheet, and the list of suggested indicators (Sample Protective Asset Outcome Indicators for Adolescent Girls and Young Women in High HIV Contexts), below, can help you determine what to measure.

\section{How to Use the Resources}

\section{Monitoring}

A Participant Register can be used for monitoring by helping you keep track of who is participating in your program according to their important characteristics. A sample register is included below as an illustration. It is important for you to decide for yourself what the most important characteristics are for the girls and young women in your program and to specify them on the register. It is not a good idea to ask for information that you already have (for example, a program for young mothers does not need to ask if a participant has ever had a child). The Intake Register, below, is an example of a participant register that can be modified to collect the information you need to monitor your own program

An Activity Register can help you keep track of your activities, how many participants there are, and how often they attend. It can help with reporting and with tracking changes over time, which can bring problems to light that can be solved by adjusting relevant aspects of the program.

\section{MONITORING}

DO

- Develop and use monitoring tools that collect information that is important for your program

- Use monitoring tools that collect information on participants and activities

- Assign responsibilities to staff responsible for the different monitoring tasks

DON'T

- Collect more information than you will use

TYPES OF INFORMATION AN ACTIVITY REGISTER
COULD COLLECT
1. Date
2. Time
3. Number of group participants and mentors/number of groups
4. Where groups meet
5. Topics covered
6. Materials distributed
7. Type of activity (e.g., group meeting, opportunity visit)
8. Quality of mentor methods used
9. Girls who have missed three meetings in a row
10. What participants like/do not like in the program
11. What changes participants would make to the program




\section{Evaluation}

Evaluation should not be left until the end of your program; it should be a central part of overall planning and design. At the beginning of the planning cycle, you should decide what type of evaluation you want to do and what will be evaluated.

It is often difficult for program staff to know what to evaluate. When you begin to think about what to evaluate, you can ask:

- What are the steps along the way-or intermediate goals-we can measure to make sure that a girl or young woman is on the right track for avoiding HIV

infection (and, more broadly, a healthy transition to adulthood)?

-What protective assets is your program giving to girls and young women to help them achieve that goal?

Measuring the set of protective assets that you want girls and young women to acquire in your program is a great way to chart its success. Your selection of specific measures should consider the variety of protective assets girls and young women need based on their age, marital status, seasonal changes in risk, and other differences. Also note that some protective assets can be acquired and measured in a short time-six months-while others take a year or more to build.

Your evaluation measures, known as "indicators," should be focused at the level of the girls or young women themselves to gauge the impact of the program. It is also helpful to measure changes at the level of the program community, such as shifts in how girls are perceived or how mobile they are.

A list of sample protective asset indicators can be helpful when you consider how to evaluate the impact of your program (see Sample Protective Asset Outcome Indicators, pg. 54).

\section{EVALUATION}

DO

- Have a clear understanding of what your program's big vision or goal is, as well as the steps along the way that girls need to achieve in order to reach that goal

- Build evaluation into your program's work plan from the very start

- Assign clear tasks and responsibilities for evaluation activities

- Conduct ongoing evaluation of program activities with the members and make program adjustments accordingly

DON'T

- Evaluate more than you have the capacity for or collect more information than you need

- Assume the evaluation is too hard, complicated, or expensive for you to do 


\section{Sample Intake Register}

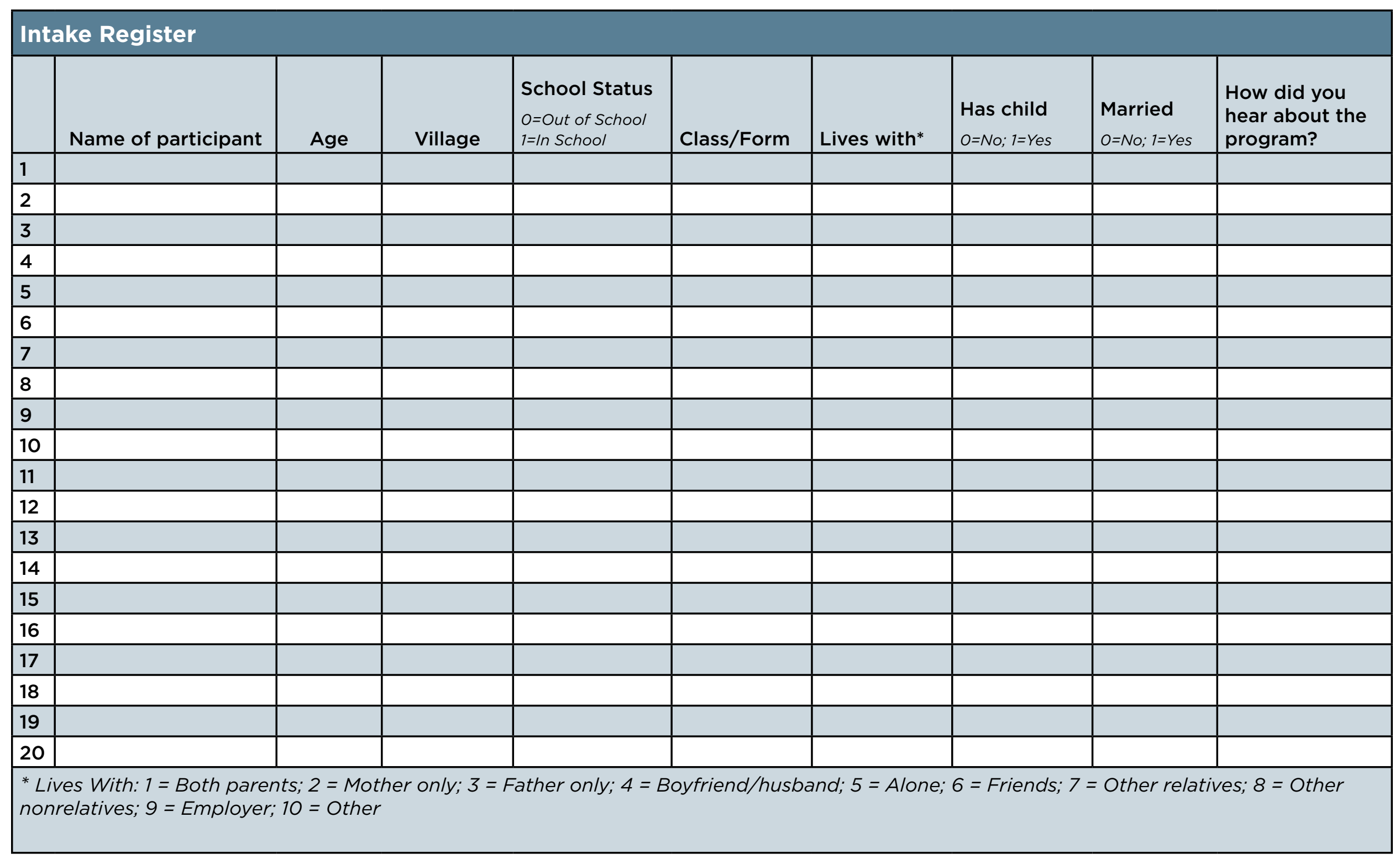




\section{Monitoring and Evaluation Worksheet}

As you think about the kind of evaluation that you are planning, one of the first steps is to decide what you want to measure. Being able to differentiate between the overall goal and vision that you have for the girls in your program, and the steps along the way that will let you know that they are on the path to reaching that goal, will simplify your evaluation work and allow you to get meaningful information.

\section{First:}

What is the overall goal and vision of your organization? What is the big, long-term goal that you have for the girls in your program?

\section{Second:}

What are the assets that you are trying to build within the girls themselves? 


\section{Third:}

What questions will you ask in order to measure each asset?

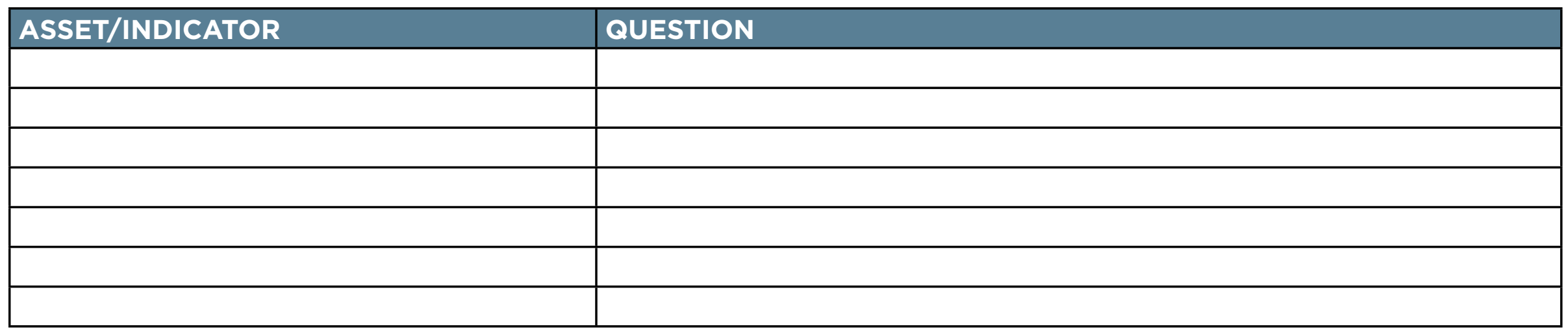

\section{Fourth:}

Think about what tools you will use to gather the information about each of these changes that you would like to measure. Will you use a short survey and include several questions? Will you have some focus groups? Use the next chart to think through the different tools:

\begin{tabular}{|c|c|c|}
\hline TOOL & ASSET/INDICATOR TO BE MEASURED & QUESTION TO BE ASKED \\
\hline E.g., Quantitative Survey & Has savings & $\begin{array}{l}\text { Do you have money put aside or in your } \\
\text { savings? (Yes/No) }\end{array}$ \\
\hline E.g., Focus Group Discussion & Understands the importance of saving & $\begin{array}{l}\text { What are some of the reasons that girls } \\
\text { like yourselves save or put money aside for } \\
\text { future use? }\end{array}$ \\
\hline & & \\
\hline & & \\
\hline & & \\
\hline & & \\
\hline
\end{tabular}




\section{Fifth:}

Now you can assign responsibilities and timelines for getting these evaluation activities in place. It is also important to think about:

a) how much money this will cost and if it is in your budget

b) do you have the in-house skills to complete these tasks or will you need to engage someone external (and the cost implications of that)

\begin{tabular}{|c|c|c|c|c|c|}
\hline TASK & $\begin{array}{l}\text { WHO WILL BE } \\
\text { RESPONSIBLE? }\end{array}$ & $\begin{array}{l}\text { DO WE NEED } \\
\text { EXTERNAL } \\
\text { EXPERTISE \& IN } \\
\text { WHAT AREA? }\end{array}$ & $\begin{array}{l}\text { HOW MUCH } \\
\text { MONEY WILL } \\
\text { IT COST? }\end{array}$ & $\begin{array}{l}\text { HOW MUCH } \\
\text { STAFF TIME } \\
\text { WILL IT TAKE? }\end{array}$ & BY WHAT DATE? \\
\hline $\begin{array}{l}\text { Finalize list of } \\
\text { assets/indicators }\end{array}$ & & & & & \\
\hline Finalize list of qu & & & & & \\
\hline $\begin{array}{l}\text { Develop evaluatic } \\
\text { tools (surveys, int } \\
\text { guides, etc.) }\end{array}$ & & & & & \\
\hline $\begin{array}{l}\text { Organize the dat } \\
\text { collection* }\end{array}$ & & & & & \\
\hline $\begin{array}{l}\text { Collect the data* } \\
\text { the actual intervie }\end{array}$ & & & & & \\
\hline Analyze the data & & & & & \\
\hline Compile reports & & & & & \\
\hline
\end{tabular}

*Note: Data collection might take place at several points during the program cycle.

Use the information in this chart to assess what can be done internally and what requires external assistance.

Calculate the total budget costs and assess how you will allocate funds and staff time. Finally, you can use all of this information to integrate the evaluation activities into your overall program work plan/timeline. 


\section{Sample Protective Asset Outcome Indicators for Adolescent Girls and Young Women in High HIV Contexts ${ }^{13}$}

The sample outcome indicators in this list have been used to track the progress of programs that aim to build girls' and young women's protective assets. According to Population Council research, these indicators can be useful in evaluating programs to reduce HIV risk among excluded young female populations.

\section{SOCIAL SUPPORT}

Percent of girls and young women who:

1. Meet regularly in a safe place with girls and young women like them

2. Have at least one trusted female friend they can confide in

3. Know a woman in their community, other than a mother or guardian, who they can turn to if they have a serious problem.

\section{PERSONAL SAFETY}

Percent of girls and young women who:

4. Have a safe place to stay overnight in an emergency.

5. Can identify five risky situations for girls and young women like them.

6. Have a specific plan to manage risky situations.

7. Can identify three places in their community where bad things might happen to them.

\section{FINANCIAL READINESS}

Percent of girls and young women who:

$$
\text { 8. Have money saved. }
$$

Of those with money saved, percent:

9. Whose savings are safe and under their own control.

10. Who plan how to use or save the money they have.

\section{Percent of young women who:}

11. Have engaged in paid work over the last 12 months (only for older adolescents and young women).

\section{SELF-EFFICACY}

Of sexually active girls and young women, percent who:

12. Are confident that they can use a condom with all sex partners.

13. Are confident that they can resist pressure to have sex.

\section{Percent of girls and young women who:}

14. Believe that they can access health services when they need them.

15. Are confident that they could get an HIV test. 
1 The DREAMS Partnership is delivering a core prevention package to address adolescent girls and young women who account for a disproportionate share of new HIV infections in sub-Saharan Africa. The partnership responds to health sector needs and also the structural drivers of girls' disproportionate HIV risk. For more information: http://www.pepfar.gov/ documents/organization/252380.pdf.

2 The Women's Refugee Commission and operation organizations of the Girls in Emergencies Collaborative.

3 "Segmenting" is dividing girls into subpopulations for programming. By breaking down target populations by segment, clustered by shared characteristics such as age, schooling, or marital status, you can assess whether you are reaching enough girls, at critical mass, to make a difference in your programming. For more information: http://siteresources.worldbank.org/ INTGENDER/Resources/336003-1280176218337/ 1_JudithBruce.pdf.

4 Elite capture: Resources designated for the benefit of a broader group are used by a few individuals with relatively better-off status. In this case, the girls with the fewest needs receive the majority of program benefits, rather than those most in need, due to inappropriate targeting.

5 On-track: Being in a state that does correspond to girls' rights and entitlements by age.

6 Off-track: Being in a state that does not correspond to girls' rights and entitlements by age, as reflected in indicators such as school enrollment status, e.g. never having attended school, currently out of school, in school but not at grade for age.
7 Community mapping originated with the participatory rural appraisal (PRA) research of Robert Chambers. See:

-Chambers, R. 1992. "Rural appraisal: Rapid, relaxed and participatory." Institute for Development Studies Discussion Paper No. 311.

-Chambers, R. 1994. "The origins and practice of participatory rural appraisal." World Development 22(7): 953-969.

-Chambers, R. 1997. Whose Reality Counts? Putting the First Last. Intermediate Technology Publications.

8 Other examples of mapping methods applied with adolescent girl groups include:

-Brady, M. 2003. "Safe spaces for adolescent girls." Background document to Adolescent and Youth Sexual and Reproductive Health: Charting Directions for a Second Generation of Programming. New York: UNFPA and Population Council, pg. 155-176.

-Austrian, K. and D. Ghati. 2010. Girl Centered

Program Design: A Toolkit to Develop, Strengthen \& Expand Adolescent Girls Programs.

-Hallman, K., et al. "The Shrinking World of Girls at

Puberty: Violence and Gender-Divergent Access to the

Public Sphere among Adolescents in South Africa,"

Global Public Health. October 2014. 10: 1-17.

9 This tool was inspired by the work of:

-Conradin, K., M. Kropac, and D. Spuhler (eds.). 2010.

The SSWM Toolbox. Basel: SEECON International GMBH. http://www.sswm.info.

-Fraser, E., A. Thirkell, and A. McKay. 2003. Tapping into Existing Social Capital: Rich Networks, Poor Connections. London, UK: Social Development Direct, Sinani, and Institute for Participatory Interaction in Development.

10 This tool was inspired by the work of Shah, M.K., S.D. Kambou, and B. Monahan. 1999. Embracing Participation in Development: Worldwide Experience from CARE's Reproductive Health Programs with a Step-by-Step Field Guide to Participatory Tools and Techniques. Wisdom from the Field.
"Social Capital Building Toolkit Version 1.2 (Thomas Sander/Kathleen Lowney). Saguaro Seminar: Civic Engagement in America, John F. Kennedy School of Government, Harvard University.

12 This tool was inspired by the work of Shah, M.K. S.D. Kambou, and B. Monahan. 1999. Embracing Participation in Development: Worldwide Experience from CARE's Reproductive Health Programs with a Step-by-Step Field Guide to Participatory Tools and Techniques. Wisdom from the Field.

13 Indicators derived from:

-Austrian, K. 2013. CAPI Questionnaire for Baseline Data Collection, Adolescent Girls Empowerment Program (AGEP).

-Austrian, K. and E. Muthengi. 2013. Safe and Smart Savings Products for Vulnerable Adolescent Girls in Kenya and Uganda: Evaluation Report.

-Erulkar, et al. 2010. Ethiopia Young Adult Survey: A Study in Seven Regions.

-Erulkar, et al. 2013. Evaluation of Biruh Tesfa Program for Vulnerable Girls in Ethiopia. Vulnerable Children and Youth Studies.

- Sarah M. Burnett et al. 2011. "Evaluation of an Intervention to Increase Human Immunodeficiency Virus Testing Among Youth in Manzini, Swaziland: A Randomized Control Trial." Journal of Adolescent Health 48: 507-513.

-Austrian, et al. 2012. Safe and Smart Savings for Vulnerable Girls in Kenya and Uganda: Evolving Model, Lessons Learned, and Recommendations.

-Austrian. 2015. CAPI Questionnaire for Baseline Data Collection, Adolescent Girls Initiative-Kenya (AGI-K). 


\section{REFERENCES}

Austrian, K. and D. Ghati. 2010. Girl Centered Program Design: A Toolkit to Develop, Strengthen \& Expand Adolescent Girls Programs. Population Council. http://www. popcouncil.org/research/girl-centered-program-design-a-toolkit-to-develop-strengthenand-expand-ado.

Bruce, J. 2011. "Violence Against Adolescent Girls: A Fundamental Challenge to Meaningful Equality." New York: Population Council. http://www.popcouncil.org/uploads/ pdfs/2012PGY_GirlsFirst_Violence.pdf.

Corbett, J., et al. 2006. "Overview: Mapping for change-the emergence of a new practice." Participatory Learning and Action 54 (13-20). http://pubs.iied.org/ pdfs/14507IIED.pdf.

Engebretsen, S. 2012. "Using Data to See and Select the Most Vulnerable Adolescent Girls." New York: Population Council. http://www.popcouncil.org/uploads/pdfs/2012PGY_ GirlsFirst_Data.pdf.

Hallman, K. 2016. "Girls' Participatory Action Quantified Tools (G-PAQT) Kit.” New York: Population Council.

Population Council. 2006. How to Conduct a Coverage Exercise: A Rapid Assessment Tool for Programs and Services. New York: Population Council. http://www.popcouncil.org/ uploads/pdfs/CoverageExerciseGuide.pdf.

—. 2015. Building Assets Toolkit: Developing Positive Benchmarks for Adolescent Girls. New York: Population Council.

Robles, Omar J. 2014. I'm Here: Adolescent Girls in Emergencies-Approach and Tools for Improved Response. New York: Women's Refugee Commission.

Weiner, A. 2011. "Assessing Equity of Access in Programs for Young People." New York:

Population Council. http://www.popcouncil.org/uploads/pdfs/TABriefs/28_AssessAccess.pdf. 


\section{PROGRAM AND RESEARCH TOOLKITS}

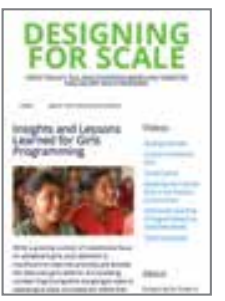

Designing for Scale: Video Toolkit on Building Evidence-

Based and Targeted

Adolescent Girls Programs

designingforscale.popcouncil.org

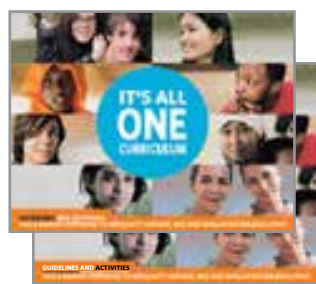

It's All One Curriculum: Guidelines and Activities

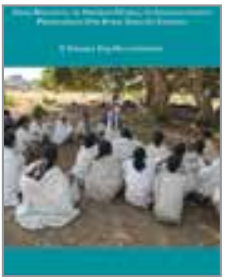

From Research, to Program Design, to Implementation: Programming for Rural Girls in Ethiopia

popcouncil.org/ethiopiagirlsprogram for a Unified Approach to Sexuality, Gender, HIV, and Human Rights Education popcouncil.org/itsallone

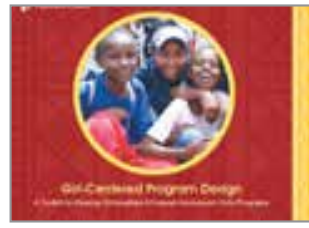

Girl-Centered Program Design: A Toolkit to Develop,

Strengthen, and Expand Adolescent Girls Programs

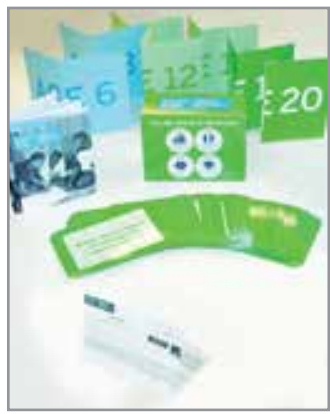

Building Assets Toolkit: Developing Positive Benchmarks for Adolescent Girls

popcouncil.org/assettoolkit

\section{RESEARCH PUBLICATIONS}

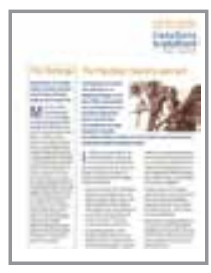

Brief Series: Promoting

Healthy, Safe, and Productive

Transitions to Adulthood

popcouncil.org/transitionbriefs

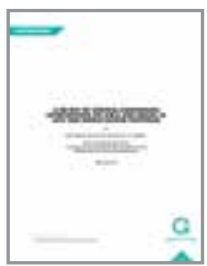

A Review of Control-

Comparison Interventions on

Girls and Health in Low-

\& Middle-Income Countries

a

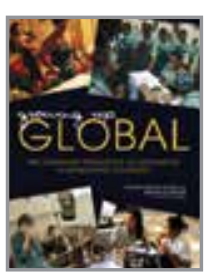

Growing Up Global:

The Changing Transitions to

Adulthood in Developing

Countries

popcouncil.org/growingupglobal

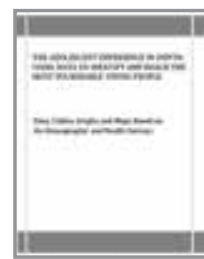

The Adolescent Experience Indepth-Using Data to Identify and Reach the Most Vulnerable Young People (Data Guides) popcouncil.org/adolgirlsdataguides

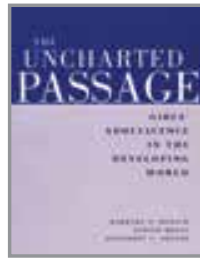

The Uncharted Passage: Girls' Adolescence in the Developing World

popcouncil.org/unchartedpassage

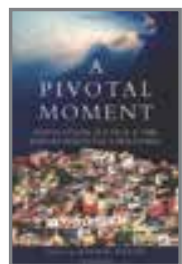

Book Chapter:

"The new population challenge"

(Judith Bruce and John Bongaarts)

in A Pivotal Moment: Population, Justice, and the Environmental Challenge

SEE ALSO: popcouncil.org/girl-centered-program-resources 
D POPULATION COUNCIL 